\title{
The origin of Ina: Evidence for inflated lava flows on the Moon
}

\author{
W. B. Garry, ${ }^{1,2}$ M. S. Robinson, ${ }^{3}$ J. R. Zimbelman, ${ }^{4}$ J. E. Bleacher, ${ }^{2}$ B. R. Hawke, ${ }^{5}$ \\ L. S. Crumpler, ${ }^{6}$ S. E. Braden, ${ }^{3}$ and H. Sato ${ }^{3}$ \\ Received 29 September 2011; revised 21 September 2012; accepted 27 September 2012; published 20 November 2012.
}

[1] Ina is an enigmatic volcanic feature on the Moon known for its irregularly shaped mounds, the origin of which has been debated since the Apollo Missions. Three main units are observed on the floor of the depression ( $2.9 \mathrm{~km}$ across, $\leq 64 \mathrm{~m}$ deep) located at the summit of a low-shield volcano: irregularly shaped mounds up to $20 \mathrm{~m}$ tall, a lower unit 1 to $5 \mathrm{~m}$ in relief that surrounds the mounds, and blocky material. Analyses of Lunar Reconnaissance Orbiter Camera images and topography show that features in Ina are morphologically similar to terrestrial inflated lava flows. Comparison of these unusual lunar mounds and possible terrestrial analogs leads us to hypothesize that features in Ina were formed through lava flow inflation processes. While the source of the lava remains unclear, this new model suggests that as the mounds inflated, breakouts along their margins served as sources for surface flows that created the lower morphologic unit. Over time, mass wasting of both morphologic units has exposed fresh surfaces observed in the blocky unit. Ina is different than the terrestrial analogs presented in this study in that the lunar features formed within a depression, no vent sources are observed, and no cracks are observed on the mounds. However, lava flow inflation processes explain many of the morphologic relationships observed in Ina and are proposed to be analogous with inflated lava flows on Earth.

Citation: Garry, W. B., M. S. Robinson, J. R. Zimbelman, J. E. Bleacher, B. R. Hawke, L. S. Crumpler, S. E. Braden, and H. Sato (2012), The origin of Ina: Evidence for inflated lava flows on the Moon, J. Geophys. Res., 117, E00H31, doi:10.1029/2011JE003981.

\section{Introduction}

[2] The enigmatic lunar volcanic feature, Ina $\left(18^{\circ} 40^{\prime} \mathrm{N}\right.$, $\left.5^{\circ} 18^{\prime} \mathrm{E}\right)$, informally known as "D-caldera" and "Ina D," has a distinct morphology whose origin has intrigued scientists since its discovery in orbital imagery from the Apollo 15 mission [Whitaker, 1972; Evans and El-Baz, 1973; El-Baz, 1973; Strain and El-Baz, 1980; Schultz et al., 2006; Robinson et al., 2010b; Staid et al., 2011]. Ina is a depression, possibly a collapse caldera, at the summit of a dome [El-Baz, 1973] or possible low-shield volcano [Strain and $E l-B a z, 1980]$ on a fault-bound horst in Lacus Felicitatis

\footnotetext{
${ }^{1}$ Planetary Science Institute, Tucson, Arizona, USA.

${ }^{2}$ Planetary Geodynamics Laboratory, Code 698, NASA Goddard Space Flight Center, Greenbelt, Maryland, USA.

${ }^{3}$ School of Earth and Space Exploration, Arizona State University, Tempe, Arizona, USA.

${ }^{4}$ Center for Earth and Planetary Studies, Smithsonian Institution, National Air and Space Museum, Washington, D. C., USA.

${ }_{5}^{5}$ Institute of Geophysics and Planetology, SOEST, University of Hawaii at Manoa, Honolulu, Hawaii, USA.

${ }^{6}$ New Mexico Museum of Natural History and Science, Albuquerque, New Mexico, USA.

Corresponding author: W. B. Garry, Planetary Geodynamics Laboratory, Code 698, NASA Goddard Space Flight Center, Greenbelt, MD 20771, USA. (william.b.garry@nasa.gov)

(C)2012. American Geophysical Union. All Rights Reserved. 0148-0227/12/2011JE003981
}

located within the ejecta blanket from the Imbrium Basin (Fra Maura Formation) [Hackman, 1966] (Figure 1). Ina is best known for the bulbous, irregularly shaped mounds that occur inside the main depression (Figures 2-4). These features were described as appearing like "dirty mercury" on the lunar surface [Whitaker, 1972] with an unmistakable bluish-gray tint visible from orbit (Figure 1b) [Evans and $E l-B a z, 1973]$. While this morphology is not unique to Ina, (e.g., crater Hyginus and locations in Mare Tranquillitatis) (Figure 5) [Schultz, 1976; Hawke and Coombs, 1987; Schultz et al., 2006; Stooke, 2012], these bulbous mounds are best formed and preserved at this site. Questions still remain, such as how did these unique geologic features form on the Moon and are there analogous geologic features on Earth that could help explain their origin?

[3] The model presented in El-Baz [1973] infers a volcanic origin for Ina and shows that mare activity began prior to the formation of the horst, but that eruptions continued after the tectonic uplift took place to form the observed dome and mounds. A qualitative model is illustrated through a sequence of six time steps in El-Baz [1973]. The model infers that the underlying terrain is highly fractured due to the Imbrium impact event and is covered by a thick ejecta blanket. These subsurface fractures and faults acted as conduits for basaltic lavas that formed a mare deposit overlying the ejecta. After initial eruptions, displacement along major faults formed the horst, but the conduits for basaltic lavas 

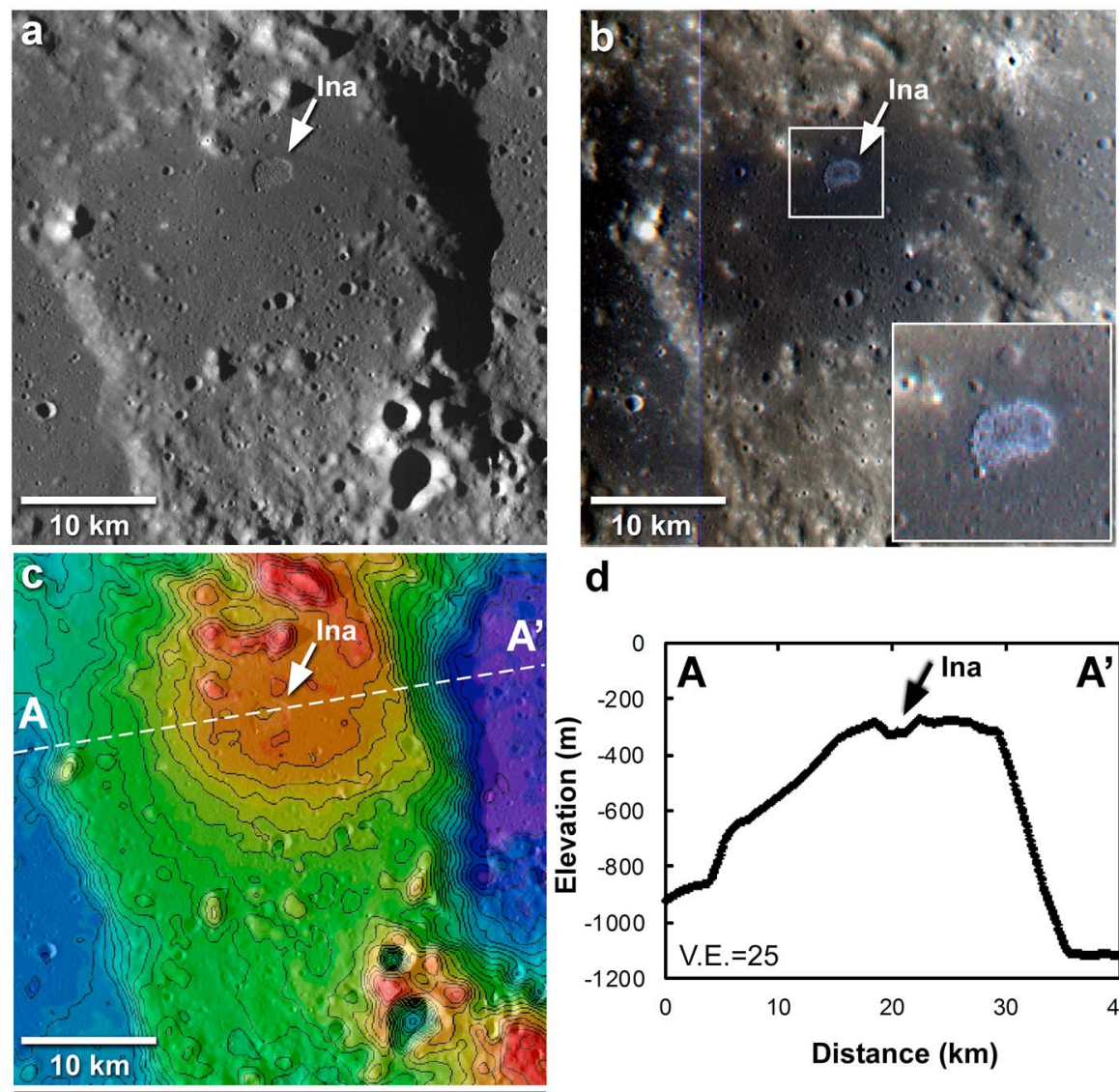

d

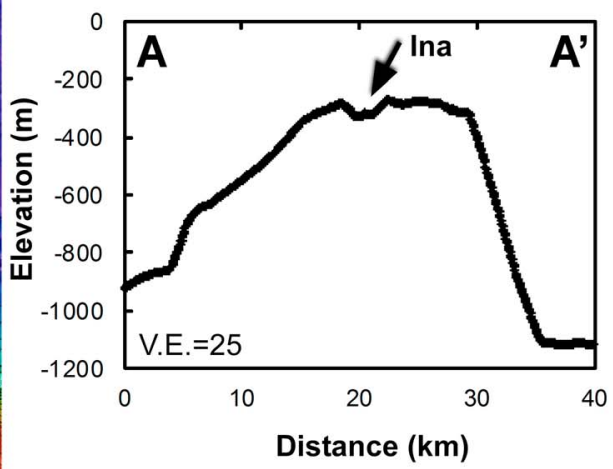

meters

$-1773$

$-568$

40

Figure 1. Ina is located at the summit of a volcanic dome situated on a horst. (a) LROC WAC monochromatic mosaic (M117454036ME, M117467600ME, $415 \mathrm{~nm}$ band). Resolution is $100 \mathrm{~m} /$ pixel. Incidence angle is $82^{\circ}$. North is up. (b) Uncalibrated LROC WAC mosaic (M150490747CE, M150483953CE) color composite: red: $690 \mathrm{~nm}$, green: $605 \mathrm{~nm}$, blue: $415 \mathrm{~nm}$. Resolution is $100 \mathrm{~m} /$ pixel. Inset shows the bluish tint associated with Ina. The white box is comparable to the images shown in Figures 2 and 3 . North is to the top of this image. (c) LROC WAC DTM overlain on LROC WAC monochromatic mosaic. Contour lines are $50 \mathrm{~m}$. The dome is $17 \mathrm{~km}$ in diameter, up to $300 \mathrm{~m}$ in relief with slopes of $2.4^{\circ}$ to $4.5^{\circ}$ along the flanks. Heights of the scarps are $300 \mathrm{~m}$ (western) to $800 \mathrm{~m}$ (eastern). Dashed white line marks location of topographic profile. (d) Topographic cross-section from LOLA gridded DTM. Figure used with permission of NASA/GSFC/Arizona State University.

remained active. Late-stage volcanism formed or continued to form the $15-\mathrm{km}$ wide dome after the formation of the horst. Collapse at the summit of the dome produced the observed depression. The model in El-Baz [1973] states that small, individual extrusions of lava onto the floor of the depression formed the numerous mounds observed in Ina, but details about the formation of the other units or basic eruption process are not given. Strain and El-Baz [1980] compare the formation of features in Ina to terrestrial volcanic features called Dimmuborgir (lava pillars) near Mývatn, Iceland. However, Strain and El-Baz [1980] note several morphologic inconsistencies with this analog that do not explain key observations, including the different elevation levels of the mounds plus the presence of moats that surround them in Ina, and instead argue that the mounds are discrete effusive features. The issue with this model is that the mounds do not exhibit individual central vent structures, nor does the model address the formation of the lower-elevation morphologic unit. While the dome on the horst is similar in dimensions to other lunar domes [Whitford-Stark and Head, 1977; Head and Gifford, 1980; Tran et al., 2011], it is difficult to compare the morphology of the mounds which are only a few hundreds of meters in scale with features that are kilometers in scale.

[4] Schultz et al. [2006] does not provide a model for the formation of the large morphologic features in Ina, but does suggest geologically recent release of volatiles has exposed patches of brighter, blocky material on the floor. In their model, a thick $(>12 \mathrm{~m})$ cover of regolith or pyroclastic material has been removed by episodic outgassing of subsurface volatiles [e.g., juvenile $\mathrm{CO}_{2}$ and possibly $\mathrm{H}_{2} \mathrm{O}$ ] to form the brighter patches of material in Ina. They state that the relict volcanic features (e.g., mounds) are at least $3.5 \mathrm{Ga}$, but that regolith has been removed within the past $\sim 10 \mathrm{Ma}$. 

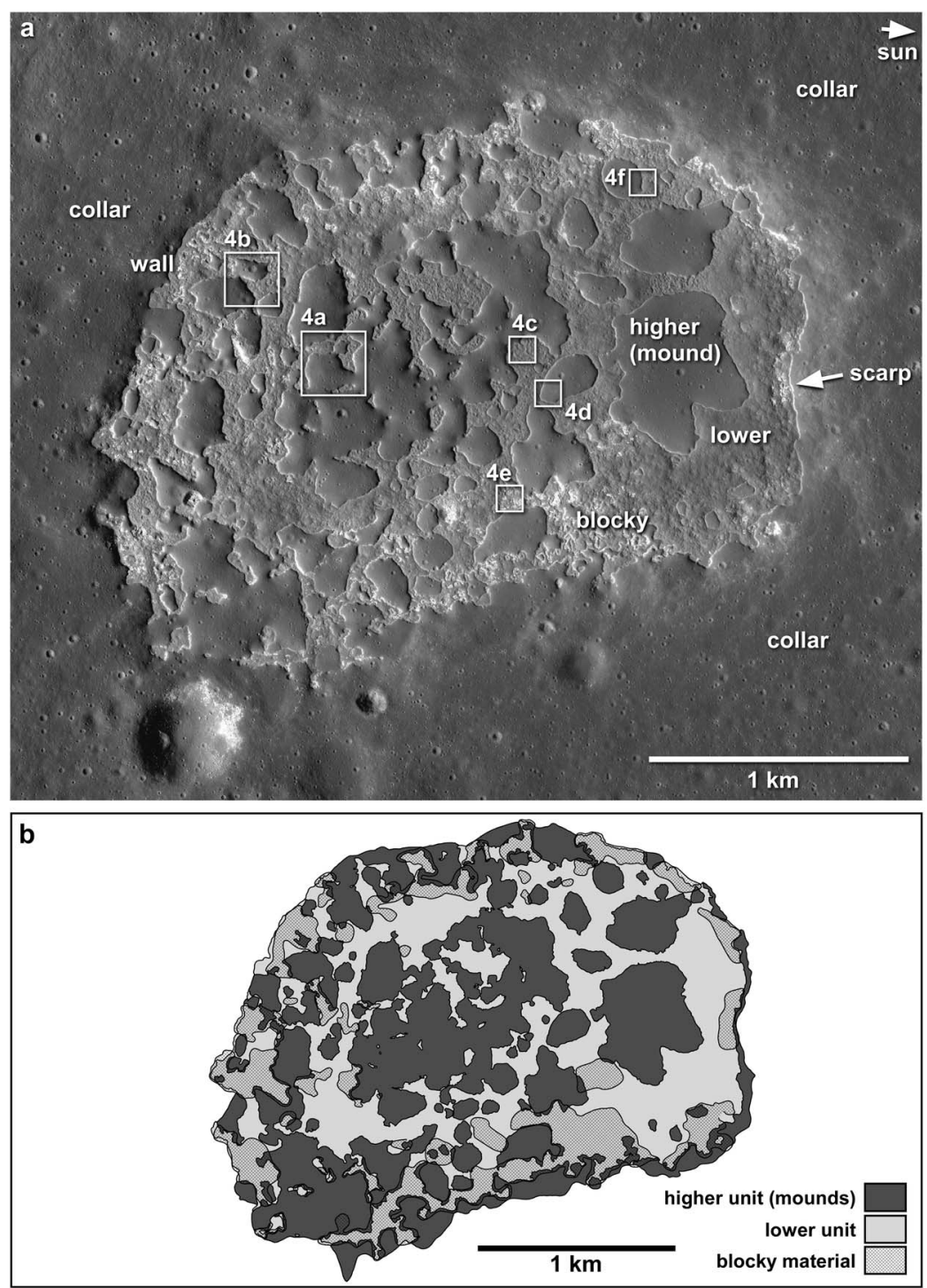

Figure 2. (a) LROC NAC (M119815703) image of Ina at a resolution of $0.5 \mathrm{~m}$ per pixel with examples of representative units labeled. Incidence angle is $55.9^{\circ}$. (b) Sketch map showing the distribution of the three morphologic units. White boxes mark locations detailed in Figure 4. Figure used with permission of NASA/GSFC/Arizona State University.

The Clementine color-ratio composite (blue, $415 \mathrm{~nm} /$ $750 \mathrm{~nm}$; green, $750 \mathrm{~nm} / 950 \mathrm{~nm}$; and red, $750 \mathrm{~nm} / 415 \mathrm{~nm}$ ) exhibits a greener area within Ina that is consistent with exposures of high-titanium basalts in impact craters in Mare Tranquillitatis [Schultz et al., 2006]. These fresh exposures correlate best to locations of the blocky material within the lower morphologic unit of Ina (Figure 2b). Other studies show that volatiles, such as radon, have been released across a broader region near Ina in the past 60 years [Lawson et al., 2005]. Schultz et al. [2006] argue that their crater counts, the presence of spectrally fresh exposures, and preservation of meter-scale features are consistent with a geologically young age for the exposures of bright, blocky material on the floor of Ina.

[5] We argue that a lava flow inflation model based on Lunar Reconnaissance Orbiter Camera (LROC) data and terrestrial field studies can more adequately explain the origin of morphologic features observed in Ina than previous models. We hypothesize that Ina experienced lava flow inflation or endogenous growth of lava flows [Walker, 1991; Hon et al., 1994]. A new model to explain the origin of Ina via these processes is presented here based on a comparison of high-resolution images from LROC [Robinson et al., 2010a] with field studies of terrestrial lava flows in New Mexico, Idaho, and Hawai'i [Bleacher et al., 2007, 2008; Garry et al., 2008, 2009; Zimbelman et al., 2009, 2010]. If the features in Ina have morphologies and dimensions comparable to certain terrestrial inflated lava flows, then these lunar features could have formed through similar inflation processes. If the features in Ina are formed by lava flow inflation processes, as suggested here, then this would be the first detailed study of a lava flow emplacement style on the Moon that is very different from the high-effusion rate, high-volume lunar lava flows that form sinuous rilles 

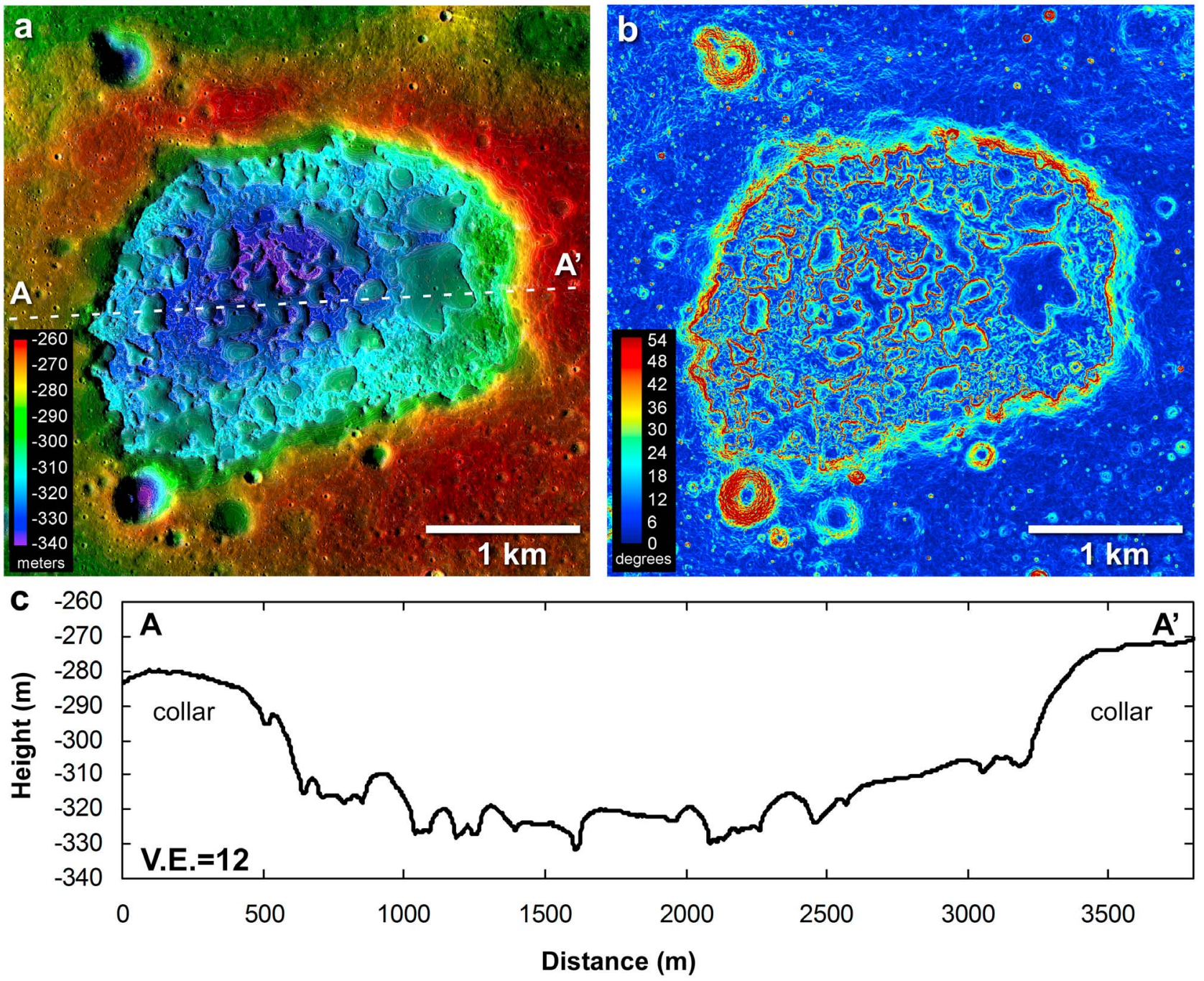

Figure 3. (a) Color-shaded topography overlain on LROC NAC image, (b) slope map, and (c) topographic profile derived from the LROC NAC DTM of Ina. Vertical exaggeration = V.E.

[e.g., Hulme, 1973, 1982] and extensive mare deposits [e.g., Schaber, 1973], however the flow lobes in Mare Imbrium may have experienced inflation [Wilson and Head, 2008]. Inflation has been suggested to explain the characteristics of outcrops along the wall of Hadley Rille and vesiculated basaltic rocks photographed by Apollo 15 [Keszthelyi, 2008] and would also be consistent with the identification of smooth plateaus and irregular depressions observed in mare units within Oceanus Procellarum and Flamsteed Ring [Schultz et al., 1976; Greeley and Schultz, 1977].

\section{Data and Analysis}

[6] High resolution images (up to $0.5 \mathrm{~m}$ per pixel scale) from the LROC Narrow Angle Cameras (NAC) allow for detailed observations of Ina. LROC Wide-angle Camera (WAC) images ( $\sim 75 \mathrm{~m}$ per pixel scale at nadir) give a regional context of the dome associated with Ina. A $2 \mathrm{~m}$ per post Digital Terrain Model (DTM) was created from two LROC NAC pairs [Tran et al., 2010] for topographic and slope analysis of Ina (Figure 3). Regional topography was analyzed from the LROC WAC $100 \mathrm{~m}$ DTM [Scholten et al.,
2011] and Lunar Orbiter Laser Altimeter (LOLA) data [Smith et al., 2010].

[7] The terrestrial field studies were conducted at inflated lava flows in Hawai'i, New Mexico, and Idaho between 2007 and 2011. A Trimble R8 Differential Global Positioning System (DGPS) with centimeter accuracy in both horizontal $( \pm 2 \mathrm{~cm})$ and vertical $( \pm 4 \mathrm{~cm})$ positions was used to obtain topographic profiles of the terrestrial lava flows.

\subsection{Ina}

[8] The diameter of the depression that forms Ina varies from 1.9 to $2.9 \mathrm{~km}$ and its shape has been compared to that of the letter $\mathrm{D}$ [El-Baz, 1973]. The rim of the depression is a relatively flat area, 600 to $1000 \mathrm{~m}$ wide, and is referred to as the collar in Strain and El-Baz [1980] (Figures 3a and 3c). The local slopes on the rim are $1^{\circ}$ to $3^{\circ}$ (Figure $3 \mathrm{~b}$ ). Relative to the rim, the depression is 30 to $40 \mathrm{~m}$ deep along the outer perimeter and has a maximum depth of $64 \mathrm{~m}$ near the center of Ina (Figure 3a). At the base of the interior wall of the depression is a nearly continuous, 6 to $8 \mathrm{~m}$ high scarp (Figure 2a). The slopes along the wall of the depression range from $5^{\circ}$ to $15^{\circ}$ and increase to $20^{\circ}$ to $30^{\circ}$ along the 

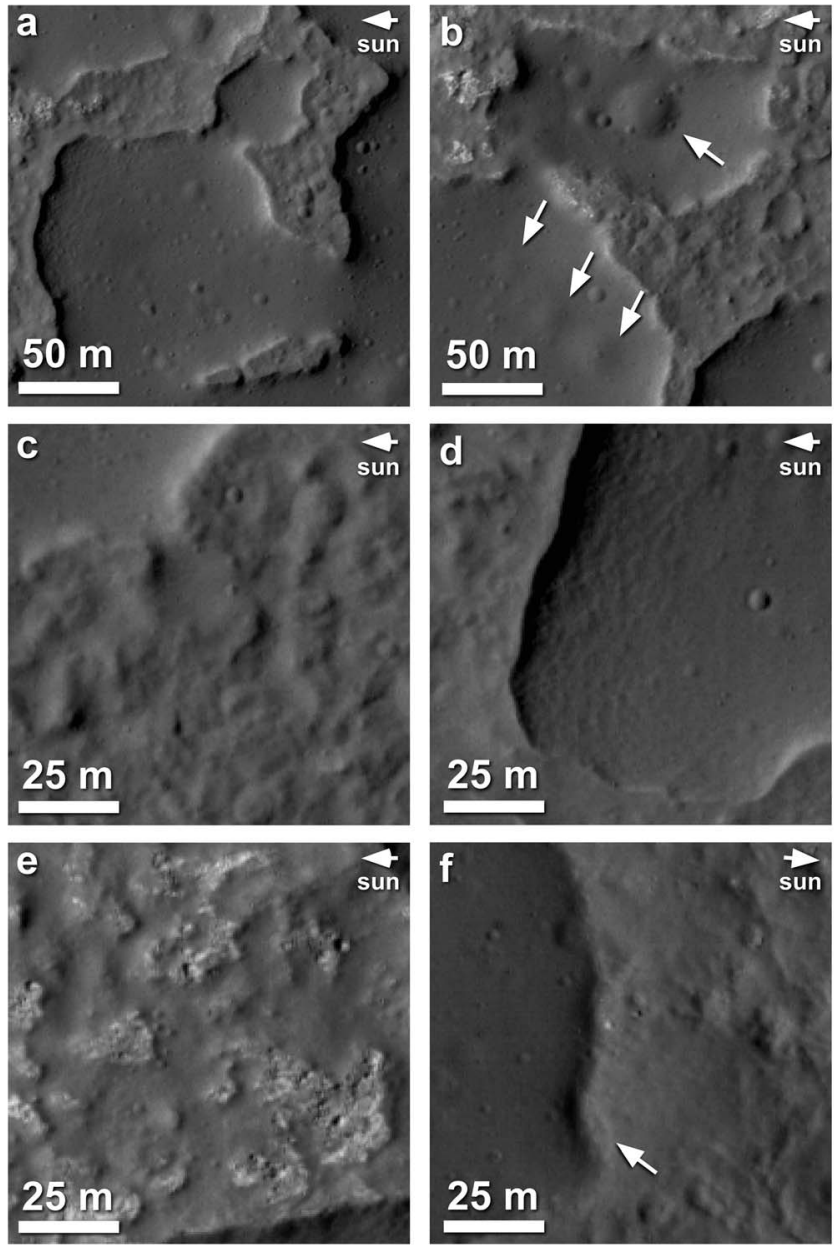

Figure 4. Examples of morphologic units and features in Ina. LROC NAC (M113921307) (0.5 m/pixel) (a) mounds, (b) buried craters on mounds, (c) lower morphologic unit, (d) elephant-skin texture on margin of a mound, (e) lower elevation unit and blocky unit, and (f) topographic moat adjacent to mound (left side of image) LROC NAC Image (M119815703) (0.5 m/pixel) Figure used with permission of NASA/GSFC/Arizona State University.

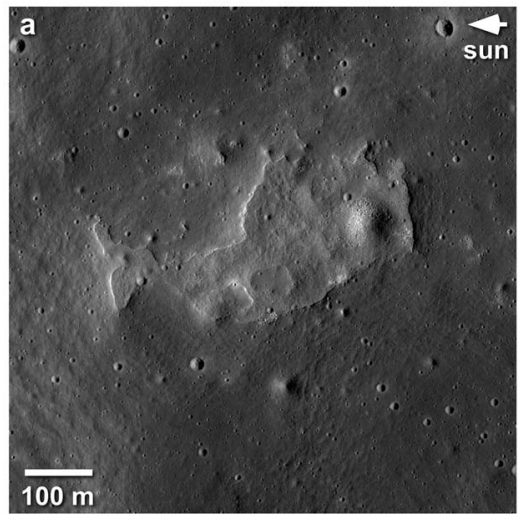

scarp. The slope from the base of the depression wall to the lowest topographic point in the depression is $1.3^{\circ}$ to $1.6^{\circ}$. This slope corresponds to a change in elevation of $\sim 30 \mathrm{~m}$ over distances of 1.2 to $1.5 \mathrm{~km}$ (measured from the outer margin to the lowest point in the depression) along the floor of Ina.

[9] Three morphologic units are observed across Ina in this and previous studies (Figures 2a and 4): 1) a higher unit, referred to here and in Strain and El-Baz [1980] as mounds (Figures 4a and 4b), 2) a lower unit, (units 1 and 2 in Strain and El-Baz, [1980]) (Figure 4c), and 3) a blocky unit (Figure 4e).

\subsubsection{Higher Unit}

[10] There are more than fifty irregular-shaped, topographically high mounds dispersed across the depression that stand alone or extend from the wall of the depression (Figure 2b). These mounds are typically higher than the other adjacent interior units (Figure 6). The margins of the mounds have a mottled, elephant-skin-like texture (Figure 4d) whereas some sections along their margins have boulders. The junctures between mounds and the wall of the depression are seamless (Figure 6c); contact margins are not observed where they appear to join together suggesting that they are comprised of, or at least covered by, the same material. The majority of the stand-alone mounds are approximately 150 to $350 \mathrm{~m}$ in length along their major axis, with some of the larger stand-alone mounds between 500 to $600 \mathrm{~m}$ in length. The minor axis is typically 100 to $200 \mathrm{~m}$ across, giving the stand-alone mounds an elongate shape (Figure 7). The largest mound, located at the center of Ina, is $1.4 \mathrm{~km}$ in length along its major axis, but appears to be comprised of mounds that are interconnected. The heights of the mounds typically range from 10 to $15 \mathrm{~m}$ with some as high as $20 \mathrm{~m}$, based on measurements from the LROC NAC DTM (Figures 6b, 6c, and 7). The topography across the surface of the mound varies between mounds. Some mounds have nearly flat tops, where the total change in relief across the top is only 1 to $2 \mathrm{~m}$ over $100 \mathrm{~s}$ of meters. Other mounds have a more asymmetric topographic profile across the top of the surface where the elevation of one side of the mound is up to $6 \mathrm{~m}$ higher than the other side (Figure 7d). Elevations typically decrease across 'bridges' or 'necks' between the interconnected

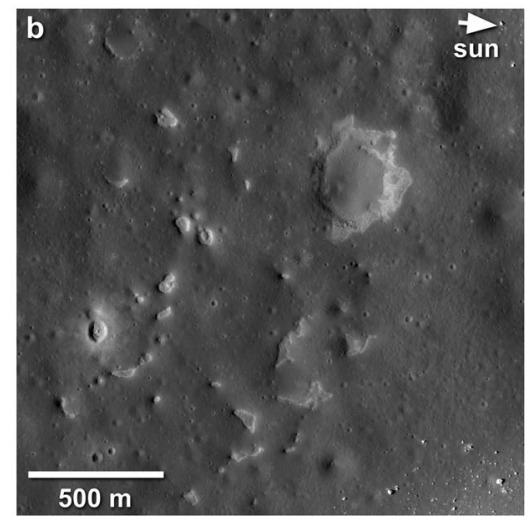

Figure 5. Other lunar surface features with morphologies that are comparable to Ina. (a) Mare Tranquillitatus $\left(8.89^{\circ} \mathrm{N}, 21.487^{\circ} \mathrm{E}\right)$, LROC NAC image M177494593RE (0.5 m/pixel, image width: $\left.750 \mathrm{~m}\right)$ incidence angle: $69^{\circ}$. (b) Hyginus $\left(7.734^{\circ} \mathrm{N}, 6.35^{\circ} \mathrm{E}\right)$, LROC NAC M104476560LE (1.25 m/pixel, image width: $1,875 \mathrm{~m}$ ) incidence angle: $53^{\circ}$. 

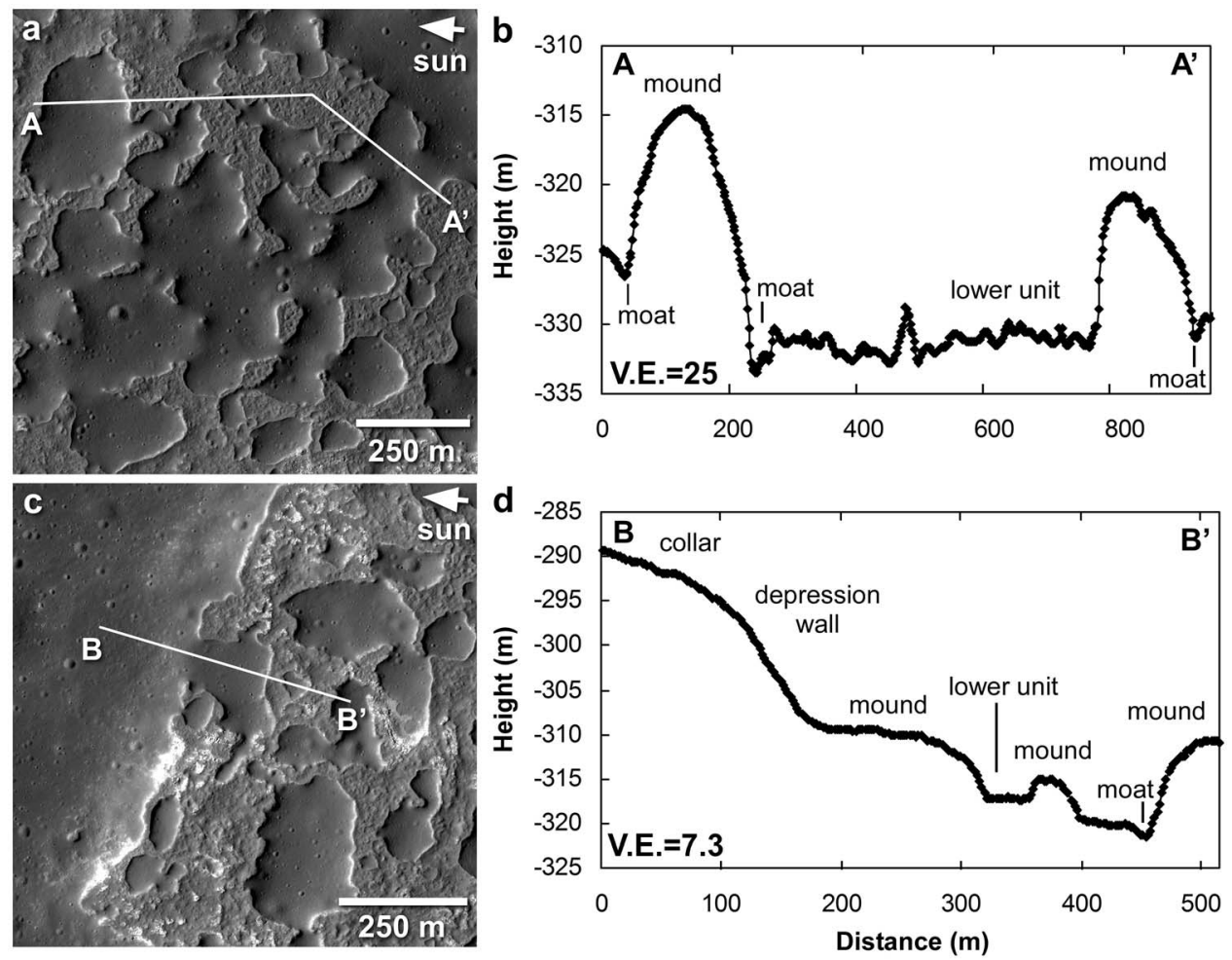

Figure 6. (a) Mounds near the center of Ina. LROC NAC (M113921307). (b) Topographic profile across mounds and hummocky and ridged terrain. Topography data is from an LROC NAC DTM. Vertical exaggeration $=$ V.E. (c) A mound connects to the margin (collar) of the caldera. (d) Topographic profile from the margin of the caldera across a mound connected to the margin. Figure used with permission of NASA/ GSFC/Arizona State University.
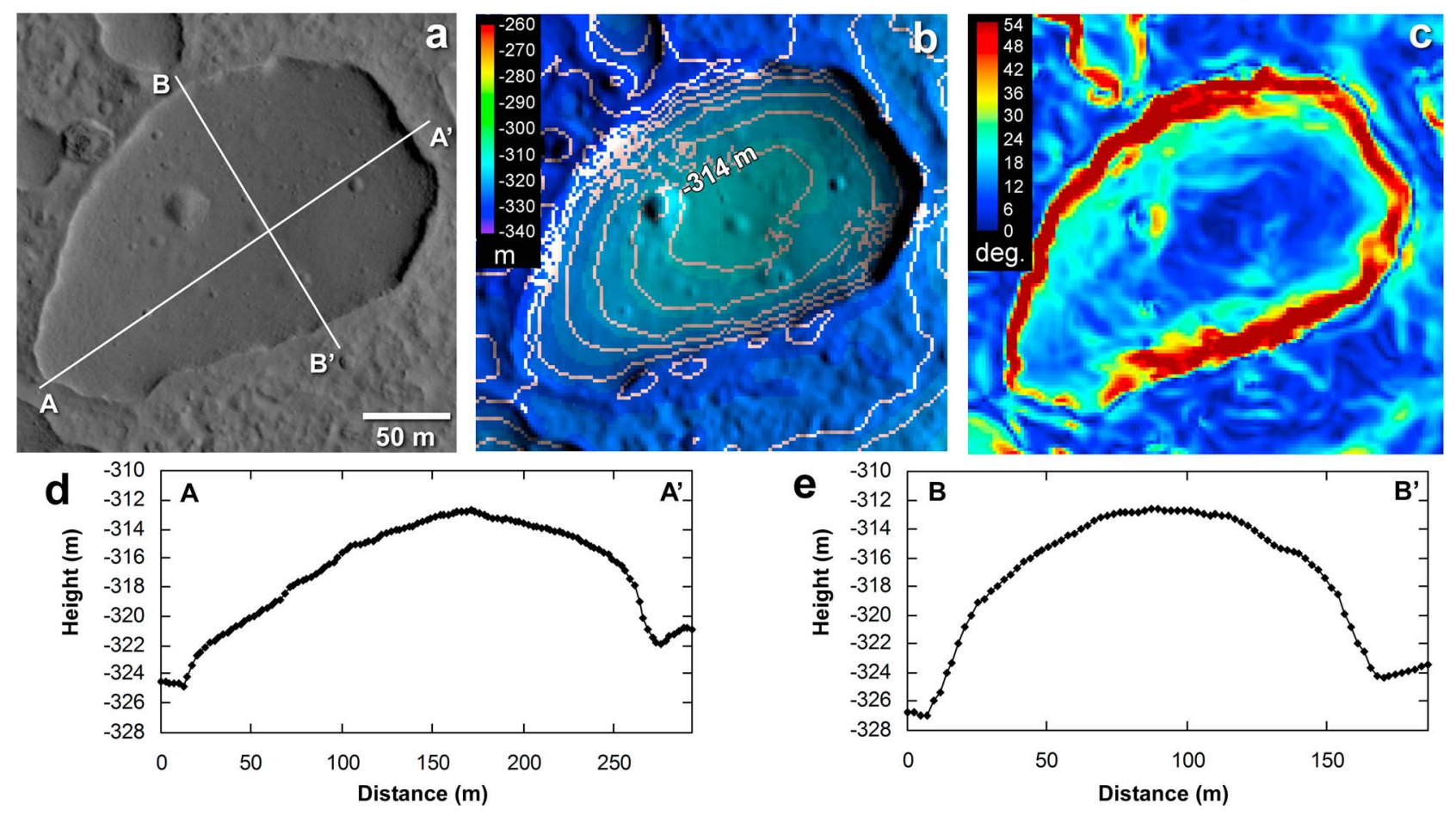

Figure 7. Morphology of a mound in Ina. (a) LROC NAC (M113921307) $(0.5 \mathrm{~m} / \mathrm{pixel})$. Locations of topographic profiles marked by white lines. (b) Topography (contour interval is $2 \mathrm{~m}$ ), (c) slope map, ( $\mathrm{d}$ and e) topographic profiles derived from LROC NAC DTM. 
sections of the large mound at the center of the depression. Near circular, rimless depressions are observed on the tops of a few mounds, offset from their center, but it is unclear if these are buried craters, surface collapse within the mound, inflation pits, or potential vent features [Strain and El-Baz, 1980; Schultz et al., 2006] (Figure 4b). There are no conclusive observations of vent-like structures at the tops of the mounds. On the tops of the mounds, slopes are $0^{\circ}$ to $5^{\circ}$ toward the center and define the edges of the mounds where slopes reach $\geq 5^{\circ}$. The margins are typically concave down, with slopes often reaching $25^{\circ}$ to $35^{\circ}$ and a maximum of $48^{\circ}$ resolved in the DTM (Figures $3 \mathrm{~b}$ and $7 \mathrm{c}$ ).

\subsubsection{Lower Unit}

[11] The lower unit that extends from and surrounds the margins of the mounds is comprised of hummocky surfaces and narrow lobes that appear intertwined (Figures $4 \mathrm{c}, 4 \mathrm{e}$, and 4f). In several locations, the lower unit appears connected to the margins of mounds (Figure 4c). While the lower unit is not all at the same topographic elevation (Figure 3a), the local relief across this terrain typically changes only 1 to $5 \mathrm{~m}$ (Figure 6b). Topographic moats a few meters deep are present where the lower unit abuts the margins of the mounds (Figures $4 \mathrm{f}$ and 6).

\subsubsection{Blocky Unit}

[12] The third unit is comprised of blocky material exposed in patches primarily around the perimeter of the depression (Figure 2). This material is mostly found within topographic lows and along the margins of the lower unit (Figure 4e) and some mounds, as well as within fresh impact craters. These blocks and boulders are approximately 1 to $5 \mathrm{~m}$ wide. Areas where the blocky unit is present with the lower unit (Figure 2b) correlate to 'greener' zones within Ina in color-ratio composites which is proposed to signify freshly exposed high-titanium basalts based on multispectral data from Clementine and Moon Mineralogy Mapper [Schultz et al., 2006; Staid et al., 2011]. High-titanium basalts were sampled by Apollo 11 and Apollo 17, but are not the most common type of basalt observed on the lunar surface [e.g., Giguere et al., 2000; Lucey et al., 2000].

\subsection{Terrestrial Inflated Lava Flows}

[13] The process of inflation occurs as lava is injected underneath a solid crust in a section of the flow and the sequence begins to rise. The growth of the liquid core is accommodated by upward motion of the crust and thickening of the flow on the order of centimeters to $10 \mathrm{~s}$ of meters [e.g., Walker, 1991; Hon et al., 1994, Self et al., 1996; Thordarson and Self, 1998]. Many lava flow inflation features such as tumuli [e.g., Daly, 1914; Cotton, 1952] and squeeze-ups [e.g., Nichols, 1939] were documented much earlier, but were not together recognized as indicators of lava flow inflation until observations of actively inflating lava flows on Kilauea volcano in Hawai'i in the early 1990s, where originally $10 \mathrm{~s} \mathrm{~cm}$ thick flows grew endogenously to meters within hours [Mattox et al., 1993; Hon et al., 1994]. Field studies of non-active flow fields on Mauna Loa and Kilauea volcanoes in Hawai'i and in the Columbia River Flood Basalts have revealed several indicators related to inflation [Rowland and Walker, 1990; Walker, 1991, 2009; Self et al., 1996; Anderson et al., 1999].

[14] Diagnostic features of inflation processes have allowed this style of emplacement to be identified in many additional lava flows on Earth that were not observed while active, as well as, on Mars, Io, and the Moon [Cashman and Kauahikaua, 1997; Self et al., 1997; Thordarson and Self, 1998; Keszthelyi et al., 2000, 2001, 2004, 2008; Bleacher et al., 2007, 2008; Kattenhorn and Schaefer, 2008; Keszthelyi, 2008; Garry et al., 2008, 2009; Giacomini et al., 2009; Zimbelman et al., 2009, 2010]. Inflation of lava flows on the Moon has been suggested to explain the meter-scale thickness of layers observed in the walls of Rima Hadley and horizontal vesicle sheets in basaltic rocks photographed by the Apollo 15 astronauts [Keszthelyi, 2008]. Lava flow inflation tends to occur when lateral spreading of lava is inhibited, often by pre-existing topography or low slope surfaces. Keszthelyi and Self [1998] state that lava flow inflation is more likely on planetary bodies with lower gravity than the Earth as the lower gravity decreases lateral spreading and provides less resistance to upward inflation. Keszthelyi et al. [2000] conclude that lava flow inflation should be prevalent across low slope basaltic environments on many solar system bodies.

[15] We have documented the surface textures and dimensions of inflation features (e.g., inflated sheet lobes, breakouts, terraced margins, lava-rise pits) at the 1859 Mauna Loa flow and lava flows in New Mexico (McCarty's, Carrizozo) [Nichols, 1946; Keszthelyi and Pieri, 1993; Zimbelman and Johnston, 2001] and Idaho (Sunset Pāhoehoe flow in Craters of the Moon National Monument, Cerro Grande) [e.g., Kuntz et al., 1986, 2007; Schaefer and Kattenhorn, 2004] through field mapping and the use of a DGPS. While our field work was not originally intended as a study for lunar analogs, the morphology and scale of the inflation features at these particular terrestrial lava flows are similar enough to Ina to prompt this comparative study. Inflation of lava flows can manifest several different morphologies in the flows. The flows we present here have some different characteristics than inflated flood basalts in the Columbia River Flood Basalts [Self et al., 1996; Thordarson and Self, 1998] and in Iceland [Keszthelyi et al., 2004]. The terrestrial inflated flows investigated here are monogenetic basaltic lavas that were emplaced on underlying surface slopes $<1^{\circ}$, not stacked sequences of multiple, large volume eruptions. The gross morphology of the flows we have documented can be subdivided into two topographic units: a higher unit (10-20 m high) comprised of broad, flat-topped plateaus with steep margins and a lower unit (1-5 m high) that is comprised of ponded lava or breakouts of pāhoehoe that surround and embay the higher morphologic unit (Figures 8-11).

\subsubsection{Higher Unit}

[16] The morphologic features that comprise the higher unit are up to $18 \mathrm{~m}$ high and $100 \mathrm{~s}$ of $\mathrm{m}$ wide (Figures $8 \mathrm{~b}$, $10 \mathrm{c}$, and 11c). Tops of the higher unit exhibit 'lineations' or 'broad parallel folds' flow textures and the relief of the surface can be nearly flat with a change in elevation of tens of centimeters to $2 \mathrm{~m}$ over $100 \mathrm{~s}$ of meter distances across their surfaces, measured with the DGPS (Figures 10c, 10d, and $11 \mathrm{c}$ ). However, some of the higher unit plateaus have an asymmetric (different margin slopes) topographic profile. The margins are monoclinal, tilted sections of crust and exhibit slopes of $20^{\circ}$ to $50^{\circ}$, with some margins near vertical (Figure 9b). Surface cracks that we have measured along the margins of the higher unit on the McCartys lava flow are 

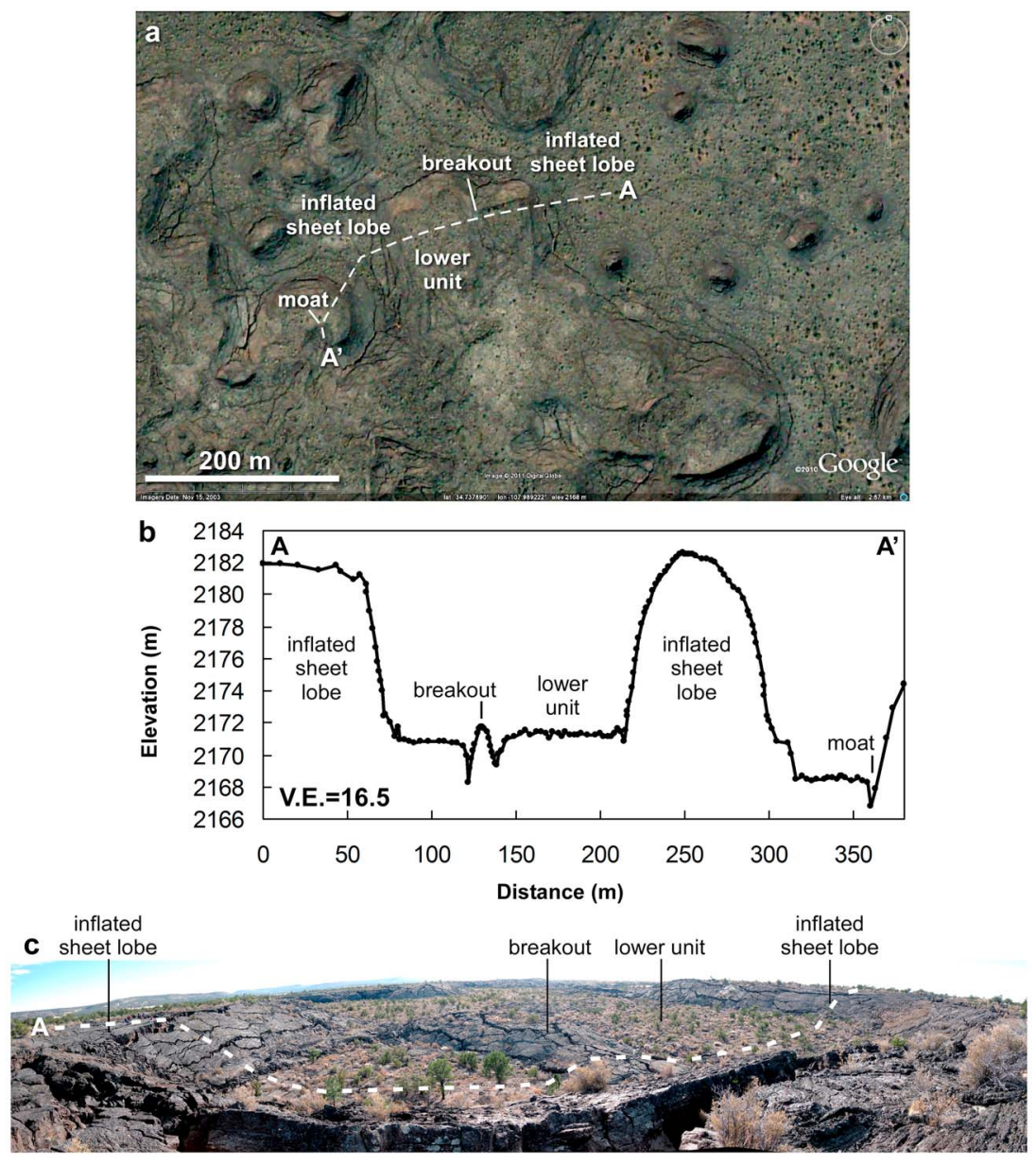

Figure 8. (a) Remote sensing image of the McCartys lava flow in New Mexico. Differential GPS traverse marked as dashed white line. Image from Google Earth. North is toward the top of the image. (b) DGPS topographic profile across the McCartys lava flow. Vertical exaggeration = V.E. (c) Panorama of the McCartys lava flow from on top of the inflated sheet lobe. DGPS traverse marked as dashed white line. View is to the south/southwest.

0.1 to $3 \mathrm{~m}$ wide and up to $8 \mathrm{~m}$ deep (Figure $8 \mathrm{c}$ ). The widest cracks we measured along a given margin typically separated the tilted crust from the flat, upper surface crust of the higher unit, as well as forming parallel and perpendicular (crosscut) to the sloped margins (Figures 8a and 9b). Finlike structures, called squeeze ups, and loose blocks are commonly observed in these cracks [e.g., Nichols, 1939]. In some instances, more fluid lava can fill the cracks partially or entirely creating a new, thin surface lobe emanating from the crack.

\subsubsection{Lower Unit}

[17] The lower unit is comprised of coalesced pāhoehoe toes, some with ropey surface textures, as well as, localized areas of ponded lava confined by the higher elevation unit (Figures 9b, 9c, and 9d). Sequences of pāhoehoe toes are interconnected and form narrow $(<10 \mathrm{~m}$ wide), lobes that interfinger each other and embay the margins of the higher unit. In several locations within the lower morphologic unit, lava has ponded and formed a smooth, slightly undulating swale-like surface as observed on the McCartys lava flow in New Mexico and the Sunset Pāhoehoe flow. The change in elevation across the lower morphologic unit terrain is 1 to
$5 \mathrm{~m}$, as measured, for example, across a section in the Sunset Pāhoehoe lava flow in Idaho (Figure 10c). Topographic moats, a few meters deep, are present where the lower morphologic unit margin has flowed near the tilted margins of the higher unit (Figures 9d and 9e).

\section{Discussion}

[18] Previous work on terrestrial inflated lava flows have provided terminology and interpretations for the morphologic features observed in the field. The higher units are referred to here as 'inflated sheet lobes' [Hon et al., 1994; Self et al., 1998], but have also been referred to as 'lava rises' [e.g., Walker, 1991], 'pressure plateaus' [Wentworth and Macdonald, 1953], and 'inflation plateaus' [e.g., Keszthelyi et al., 2004] (Figure 8a, 9a, 10a, and 11a). The surface textures on the surface of the inflated sheet flows (e.g., lineations, broad folds) indicate that these flows were initially emplaced as broad sheets of lava that later inflated to form the higher plateau-like morphology. While the relief across the surface is commonly flat, differential inflation can cause overall elevation differences of a few meters across the 

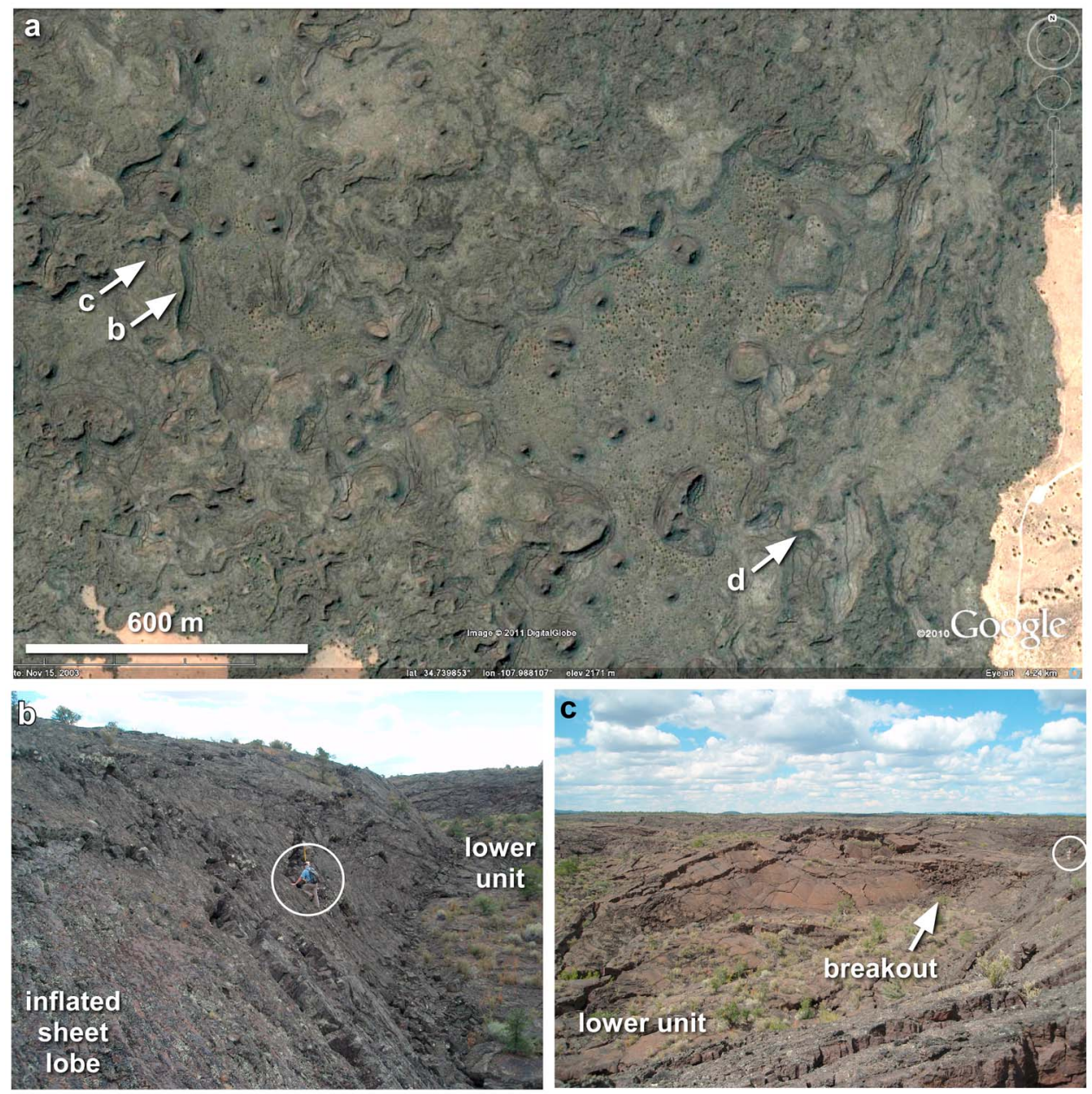

d

e
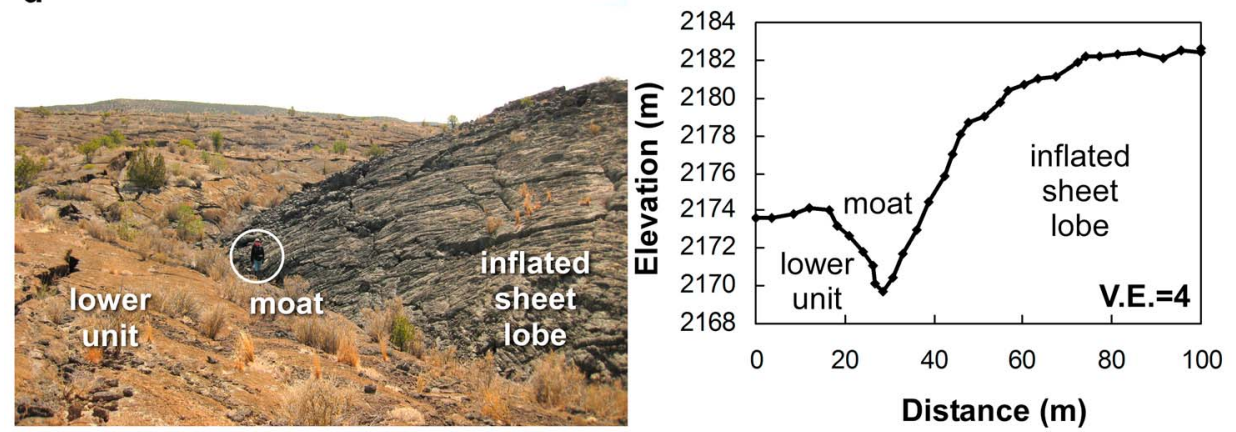

Figure 9. Inflation features and field observations at the McCartys lava flow, New Mexico. People are circled for scale. (a) Remote sensing image McCartys. Arrows show locations of photos. (b) Inflated margin of a sheet lobe, $14 \mathrm{~m}$ high. (c) Breakout from the inflated sheet lobe transitions into the hummocky and ridged terrain. (d) Topographic moat forms where lava embays the margin of an inflated sheet lobe. (e) Differential GPS topographic profile across 'moat' shown in 6d. Vertical exaggeration = V.E.

top of the same inflated sheet lobe, giving it a more asymmetric (tilted) topographic profile. Field observations suggest that the cracks along the margins of inflated sheet lobes form along inflection zones when inflation is occurring and the rigid outer crust must break to accommodate the increase in volume [Hon et al., 1994]. Cracks that form along the margins of the inflated sheet lobes, commonly referred to as 'lava-inflation clefts', indicate that the lava crust was 0.1 to $1.0 \mathrm{~m}$ thick at the onset of inflation [Walker, 1991], however inflation can still occur even after crusts thicker than $1 \mathrm{~m}$ have formed in non-pāhoehoe lava flows [Keszthelyi et al., 2004].

[19] The lower unit is comprised of pāhoehoe breakouts (Figures $8 \mathrm{c}$ and 10b). The surface textures (e.g., ropes, smooth toes) indicate low flow rates and strain rates for the lava in this unit [e.g., Rowland and Walker, 1990; Gregg and Keszthelyi, 2004]. The breakouts in the lower morphologic unit originate along the margins of the inflated sheet lobes 

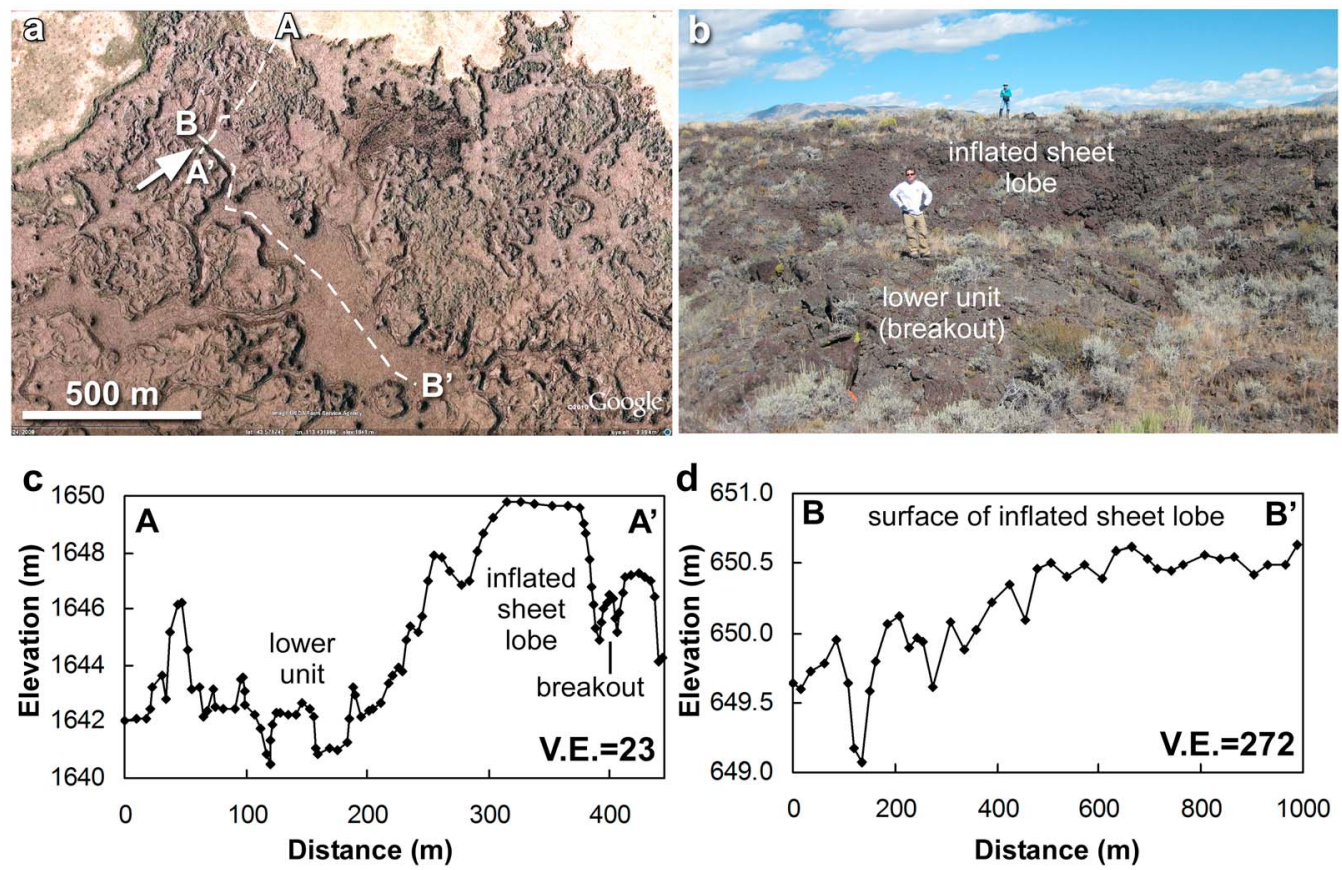

Figure 10. (a) Remote sensing image of the Sunset Pāhoehoe flow, Craters of the Moon National Monument, Idaho. Differential GPS traverses are marked by solid white lines. Arrow marks location of field photograph. (b) Field perspective of the elevation difference between an inflated mound (background) and a breakout (foreground). (c) DGPS profile from the flow margin, over the hummocky and ridged terrain, to a mound. Photo location is at the 'breakout'. Vertical exaggeration = V.E. (d) DGPS profile across the top of the inflated mound shows a difference in elevation of $1.5 \mathrm{~m}$ over $1 \mathrm{~km}$.

(higher unit) (Figures 9c and 10b). We have observed several source locations of these breakouts in the field (Figure 10b). These source locations are typically characterized by disturbed pieces of crust on the tilted margin of the inflated sheet lobe that surround an opening where lava with a more horizontal (not tilted) orientation and different surface

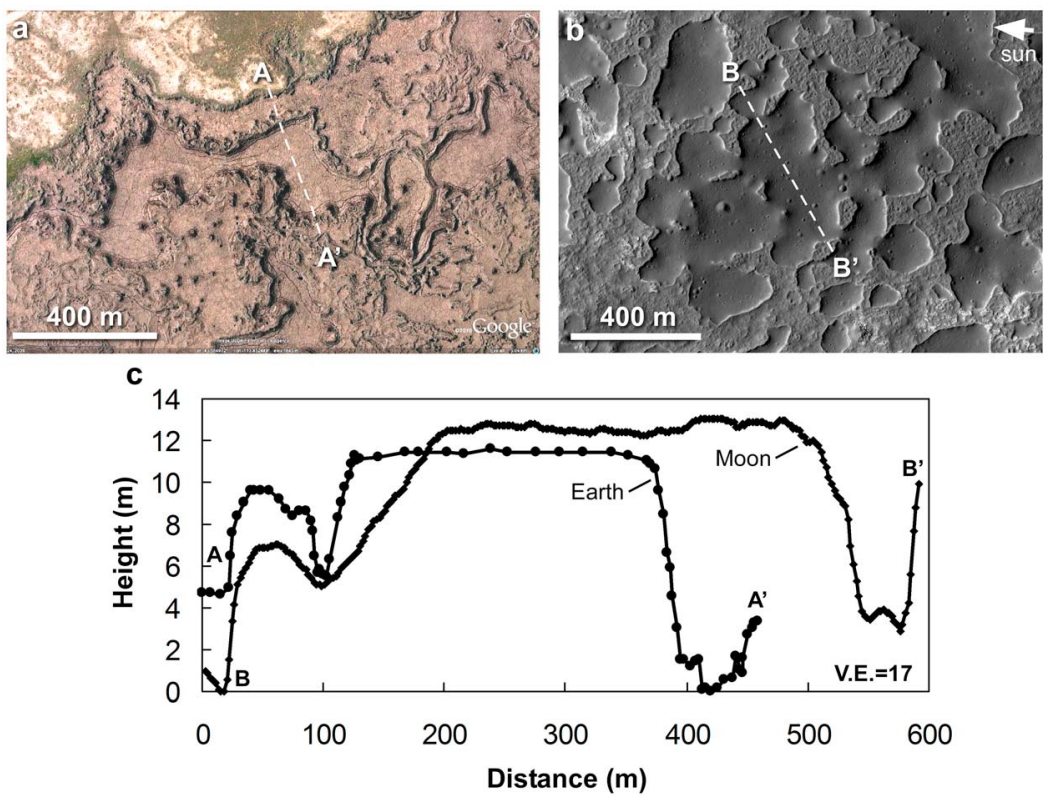

Figure 11. (a) Remote sensing image of the Sunset Pāhoehoe flow, Craters of the Moon National Monument, Idaho. Differential GPS traverse in 11c marked by dashed white line. (b) Mounds near the center of Ina. Topographic profile in 11c marked by dashed white line. (c) DGPS profile from the flow margin over an inflated sheet lobe on Earth compared to an LROC NAC DTM topographic profile across a mound in Ina on the Moon. Elevations have been normalized to a common zero point. Vertical exaggeration = V.E. 
textures has extruded out. Field observations show the flows that form the lower morphologic unit did not all occur at the same time, but as staggered events during the emplacement and inflation process of the flow fields. Some source locations for breakouts are observed high along the margin of the inflated sheet lobes and are also inflated, indicating some breakouts may have occurred along the margins of the inflated sheet lobes before they had reached their final height (Figure 9c).

[20] Ina shares some similar attributes with inflated terrestrial flows, but also displays some differences. As such, we present a model based on observations of inflated terrestrial lava flows that is consistent with many of the observed features of Ina, and discuss possible explanations for the differences, which might also be tested with future observations. Similarities include the morphology and dimensions of the higher units and the lower units, while differences include eruption environment and a lack of noticeable cracks and lava-rise pits in Ina. The size, shape, and scale of the terrain in Ina are especially similar to those of features observed at the McCartys, Sunset Pāhoehoe, and Cerro Grande lava flows. Both the lunar mounds and the terrestrial inflated sheet lobes (higher unit) we have documented vary from circular to irregular planform shapes with slopes along the margins typically between $10^{\circ}$ and $50^{\circ}$ and flat to rounded tops (Figure 11). Both the lunar and terrestrial features we measured in New Mexico, Idaho, and Hawai'i comprise areal dimensions of $100 \mathrm{~s} \mathrm{~m}$ wide and relief of 10 to $20 \mathrm{~m}$ (Figure 11). The relief across the lower elevation unit in Ina and the terrestrial flows is 1 to $5 \mathrm{~m}$ (Figures $6 \mathrm{~b}, 8 \mathrm{~b}$, and 10c) and corresponds to terrains with a very convoluted texture. Topographic moats also occur along the contacts between the lower elevation unit and the mounds or inflated sheet lobes (Figures 4f and 9d). The overall underlying slope from the margin to the center of Ina is $\leq 1.5^{\circ}$, very close to the $<1^{\circ}$ regional slopes measured at the inflated terrestrial flows.

[21] Some visible differences between Ina and the terrestrial flows include the geologic setting and the lack of cracks and lava-rise pits on the mounds in Ina. The inflation features at Ina are restricted to a shallow depression a few kilometers across which is unlike the terrestrial examples we present where the features are distributed across entire flow fields several kilometers wide and tens of kilometers long. However, inflation features often occur within these terrestrial flow fields where local topographic barriers and subtle slopes as low as a couple of degrees, can confine a flow. Hon et al. [1994] describe the emplacement of several inflated sheet flows in the Hawaiian town of Kalapana in 1990. As the flows entered the town they encountered a pair of 3-5 m high ridges. These ridges served as barriers that slowed the lateral spread of the flow, thereby driving inflation. Therefore, although many terrestrial inflated flows are not confined to significant depressions, even minor topographic barriers can cause the onset of flow inflation. The surrounding scarp that defines the Ina depression was more than adequate to establish a geologic setting that on Earth has influenced the development of inflated flow fields.

[22] Cracks are an important and essential characteristic of inflated lava flows. In terrestrial flows, cracks form as the outer brittle crust fractures to accommodate the expansion of the liquid core during inflation. The width of the crack is related to the geometry of how the crustal pieces have moved apart from each other during inflation [Walker, 1991; Hon et al., 1994]. The depth of the crack is related to the thickness of the brittle crust and the location of the transition to the visco-elastic layer. The brittle crust of an actively inflating lava flow on the Earth is often extensively fractured by shallow cracks and as such has little to no tensile strength [Hon et al., 1994]. Therefore, the visco-elastic layer beneath the rigid crust is what contains the liquid core, not the solid crust [Self et al., 1997].

[23] Hon et al. [1994] presented observations of inflating lava flows at Kilauea from 1983 to 1990 . Their work provided insight into the rate of inflation and the associated ratio of brittle crust to visco-elastic core throughout the emplacement of the flow. They observed a rapid early inflation stage during which a flow was nearly entirely liquid, with minimal crust formation at the surface. At this time growth of the liquid core drove inflation of the flow. As cooling produced a brittle crust and the ratio of crust to liquid core increased, the thickness of the liquid core became essentially constant, and the inflation rate of the flow decreased. After this time continued inflation was essentially accommodated by growth of the crust as the liquid core remained the same thickness. Hon et al. [1994] warn that their model is explicit to the cooling conditions in Hawai'i, and for those lavas specifically. Subsequent research has shown that this model can be used to estimate terrestrial crust growth rates with up to $25 \%$ error [Self et al., 1998; Keszthelyi et al., 2004], with the greatest sensitivity to cooling (and crust formation) resulting from the efficiency of atmospheric convective cooling in the early stages of crust formation [Keszthelyi and Denlinger, 1996]. However, Keszthelyi and McEwen [1997] show that vesicularity is the key parameter that determines cooling rate on airless bodies, with denser lava flows cooling more slowly.

[24] Assuming the lava flow inflation model is the primary mechanism responsible for the development for the features in Ina, cracks would have formed, but why are they not observed in Ina? LROC NAC frames of Ina have resolutions of $\sim 0.5 \mathrm{~m} / \mathrm{pixel}$, therefore, fresh cracks $\geq 0.5 \mathrm{~m}$ wide can be recognized under the right lighting conditions, with ideal incidence angles $>50^{\circ}$. Some of the best preserved cracks on the lunar surface are observed on relatively fresh impact melt flows and ponds, with great examples present at crater Giordano Bruno, where cracks $<1-5 \mathrm{~m}$ wide are preserved and visible on a melt flow in LROC NAC frames (see Figure 4 in Bray et al. [2010], LROC NAC frames M106209806R and M101476840L). The widths of the cracks observed at crater Giordano Bruno are similar to the marginal cracks we have observed at the McCartys flow which are on the order of 1-3 m wide and 7-9 m deep and are visible in remote sensing images with comparable resolutions to LROC NAC frames. Not all cracks observed along the margins of inflated terrestrial mounds are meters wide and deep. As an example, some cracks observed along the margin of an inflated sheet lobe on the Cerro Grande flow were only $10-15 \mathrm{~cm}$ wide and $\leq 1 \mathrm{~m}$ deep, but these dimensions were not typical for the entire flow field. Cracks, $10 \mathrm{~s} \mathrm{~cm}$ wide and deep, are distributed along the tilted margins of the inflated sheet lobes, oriented parallel and radial to the marginal cracks, but are not as apparent in remote sensing images. Considering the morphologic features in Ina are similar in dimensions to the inflated flows 
that we have studied, we should expect cracks of comparable widths to have formed during the emplacement of Ina.

[25] Cracks should be most prominent along the margins of mounds in Ina, and the largest cracks would be expected at the transition points between the high slopes on the margins and the lower slopes that characterize the tops of the mounds. The terrestrial inflated sheet lobes we have measured transition from steep margins to nearly flat tops. Most mounds in Ina exhibit a more curved top (Figures $7 \mathrm{~d}$ and $7 \mathrm{e})$, therefore, based on the distribution of slopes we could expect several narrow cracks distributed along the crust to accommodate for inflation versus a prominent wide crack at the hinge points. The crust may have accommodated to inflation through narrow $(<0.5-1 \mathrm{~m}$ wide), shallow $(<1 \mathrm{~m}$ deep) cracks along the margins, implying that a thin lava crust remained during inflation.

[26] One explanation as to why cracks are not observed in Ina is that any centimeter- to meter-scale cracks that would have formed on the mounds have degraded over time through impacts and/or buried by the development of regolith [Hörz, 1977; Wilcox et al., 2005]. Campbell et al. [2009] have used Earth-based 70-cm wavelength radar data to show that lava flow textures can be visibly erased when the upper 2-5 $\mathrm{m}$ of bedrock is crushed and mixed during regolith formation, which is comparable with the estimates of regolith depth (4-10 m) in on the lunar maria, which increases in thickness with age [McKay et al., 1991]. Some of the craters on the mounds appear buried with no fresh rims or visible ejecta blankets (Figure 4b), but the relief across the lower morphologic unit of 1 to $5 \mathrm{~m}$ suggest that a thick regolith has not formed in the depression. The mottled texture exhibited along the margins of the mounds could be the result of regolith creeping downslope or degraded and partially buried cracks (Figure 4d).

[27] The formation and thickness of regolith would be related to Ina's age which is not well constrained. The mare material on and surrounding the horst was mapped as Imbrian in age by Hackman [1966] and then later as Eratosthenian in age by Wilhelms and McCauley [1971]. However, crater densities around the base of the dome are greater than near the rim of the depression indicating a relatively younger age for material in and around Ina $[\mathrm{El}-\mathrm{Baz}$, 1973; Strain and El-Baz, 1980]. The ages of the individual morphologic units in Ina are not well-constrained either. Schultz et al. [2000, 2006] states that the mounds are relict volcanic features at least $3.5 \mathrm{Ga}$, but argues that the age of the bright patches in Ina should be measured in the millions of years old, possibly as young as $10 \mathrm{Ma}$, not billions of years old based on comparisons with degradation and preservation of meter-scale features related to impact craters at the Apollo 16 landing site. However, LROC NAC-based crater count statistics by Robinson et al. [2010b] on both the upper and lower units in the depression, as well as, the surrounding mare unit, indicate that lower unit in Ina is much older than the $10 \mathrm{Ma}$ age reported by Schultz et al. [2006].

[28] A process described by Stofan et al. [2000] in a study of Venusian domes using Magellan data may provide an alternative explanation for the lack of cracks in Ina. These features are also flat-topped and steep-sided volcanic features, but are $10-100 \mathrm{~km}$ in diameter and average $700 \mathrm{~m}$ high [Head et al., 1991; Pavri et al., 1992], a vastly different scale from that of the mounds in Ina. Stofan et al. [2000] suggest an "annealing" mechanism to explain the lack of circumferential cracks along the margins of the flat-topped domes. Radial cracks are present on the domes. Their proposed model focused on the cooling conditions at Venusian atmospheric temperatures and implied a condition in which a balance is established between crustal cracking and inflation of a dome's liquid core to facilitate its endogenous growth. In this model the cracks are essentially healed and filled in by the inflating liquid core as the entire feature expands, potentially suggesting a rapid inflation rate relative to the crustal growth rate.

[29] Lava-rise pits are another feature typically observed within terrestrial flow fields that appear to be absent from the Ina mounds. These pits are nearly circular to irregularly shaped depressions formed by localized non-inflated portions within the sheet lobe, often due to topographic variations in the underlying pre-flow surface that hinder the supply of the lava within the sheet to localized areas [e.g., Walker, 1991; Hon et al., 1994]. Lava-rise pits are abundant in some terrestrial inflated sheet lobes, but do not always occur. Hon et al. [1994] and Self et al. [1998] state that the roughness of the pre-flow surface complicates the final morphology, leading to an irregular or hummocky surface. They suggest that relatively rapid, continuous emplacement over smooth, shallow slopes favors the formation of inflated sheets. Some inflated sheet lobes observed on the Cerro Grande flow have no lava-rise pits, and few are found within the 1859 Mauna Loa flow compared with both the McCartys and Carrizozo flows where pits are abundant. While the majority of mounds in Ina do not exhibit pits on their surface, except for impact craters, there are a few locations within the elongate mound at the center of Ina that could be lunar lavarise pits (Figure 4a). Much like the absence of inflation cracks on Ina mounds, the apparent lack of lava-rise pits suggests that the emplacement of lava on the floor of the Ina calderalike depression would have involved a steady and continuous supply of lava onto a smooth, pre-existing surface and/or feeding a pre-existing pond of lava on the floor.

[30] We suggest that Ina formed through lava flow inflation processes based on the comparisons with our field observations, as reported above. Although our observations cannot completely rule out the possibility of previously published models [El-Baz, 1973; Strain and El-Baz, 1980; Schultz et al., 2006], we argue that the concept of lava flow inflation can reasonably explain the morphologies observed in Ina. Within this model the mounds and lower unit in Ina would have formed through sequences of events similar to those forming inflated sheet lobes in terrestrial lava flows. The mounds in Ina are sections of sheet lobes or remnant ponded lava covering the floor of the depression that were inflated 10 to $20 \mathrm{~m}$ higher than their original flow thickness. Locations where the mounds in Ina transition to the lower elevation unit are interpreted to be breakouts of the lava from the interior of the mounds to feed the hummocky terrain and narrow lobes. Lava continued to propagate around the mounds through a complex sequence of breakouts and inflation. Topographic moats formed at places where lava in the lower unit encountered and inflated along the margins of the mounds.

[31] Several complex observations must be explained by a model of Ina formation including: the formation of the volcanic dome and summit depression, the shapes and elevation 
differences between the mounds and lower unit, the connection of some mounds to the wall of the depression, and the spectrally immature blocky unit. While the source location of the lava remains unclear at present (i.e., a lava lake eruption style, single or multiple vents in the depression, vents located along the collar of the depression, or lava flowing into a pre-existing depression from another source area), the application of a lava flow inflation model can still explain several key observations and morphologic relationships in Ina that are consistent with field observations of terrestrial inflated lava flows, as well as how the final morphology originated, which is not satisfactorily explained in the previous volcanic model [El-Baz, 1973; Strain and $E l-B a z, 1980]$. Lava flowing into the depression, either from an external source vent or multiple vents around the collar, provides an elevation difference that creates a hydraulic head necessary to facilitate inflation. A similar relationship was observed in the 1859 Mauna Loa flow (Hawai'i), where the distal end of the pāhoehoe flow unit was inflated after the flow encountered the coastal plain [Rowland and Walker, 1990]. The flow rate of the lava would be influenced by the lunar gravity as it flows into the depression rather than by a pressurized vent, possibly creating a flow rate low enough to facilitate inflation and not completely disrupt the crust (as would be anticipated in a turbulent flow). Mounds and the lower unit are not observed on the collar or the flanks of the dome, only inside the depression. This suggests these features are related to the final stages of an eruption. An alternative source of lava could be effusion from fractures around the perimeter of the depression floor. This could be similar to observations of active lava lakes where lava sometimes flows inward from the perimeter. Current topography across the floor of Ina (Figure 3a) requires lava to have flowed from the perimeter toward the center of the depression to form the features. A centrally located source would require lava to flow upslope toward the margins based on current topography. For this model to be considered, the central area of the depression would have to have been pressurized and elevated $\sim 35 \mathrm{~m}$ during the eruption allowing lava to flow toward the wall of the depression and then deflated to its current elevation after the eruption ceased.

[32] Strain and El-Baz [1980] suggested that each mound was formed by discrete effusion events. An extremely low effusion rate $\left(<10^{-6} \mathrm{~m}^{3} \mathrm{~s}^{-1}\right)$ or a sequence of episodic eruptions are inferred to be necessary to form domes on the Moon for a basaltic lava assuming a viscosity of $\left(10^{2} \mathrm{~Pa} \mathrm{~s}\right)$. The alternatives include a higher viscosity lava $\left(10^{6} \mathrm{~Pa} \mathrm{~s}\right)$, evolved lava compositions (andesites), or basaltic lava that contains $>30 \mathrm{vol} \%$ crystals or vesicles [e.g., Gregg and Fink, 1996]. However, the overall morphologies of mounds in Ina are not consistent with those of lunar domes [Pike, 1978; Head and Gifford, 1980]. While some mounds do have rimless depressions at the top, there is no definitive indication of source vents observed at the tops of any of the mounds in the LROC NAC images as proposed in previous studies, and these rimless depressions could be craters buried by ejecta from subsequent impacts (Figure 4b).

\section{Conclusion}

[33] Data from LRO have provided new insight into the origin of Ina. Analysis of high resolution LROC NAC images and DTM show that the mounds and lower unit in Ina are similar to terrestrial inflated lava flows in New Mexico, Idaho, and Hawai'i. Our field observations and Differential GPS measurements of terrestrial lava flows (McCartys, Cerro Grande, Sunset Pāhoehoe, Mauna Loa 1859) show that relationships between the high, inflated sheet lobes and breakouts that form a surrounding lower unit are consistent with observations of the higher mounds and lower unit in Ina. The higher units have circular to irregular shapes, steep margins (up to $48^{\circ}$ ), heights up to $20 \mathrm{~m}$, and flat to rounded tops that change by only a few meters in height across surfaces spanning $100 \mathrm{~s}$ of meters. The lower units are comprised of narrow lobes, which extend from, surround, and embay the higher unit. Both lower units exhibit a change in relief of 1 to $5 \mathrm{~m}$ across each terrain. Several morphologic relationships observed in Ina are addressed by a lava flow inflation model, which are not explained or supported in previous work that suggested that individual eruptions or degassing of volatiles resulted in the observed morphology. Differences between inflated terrestrial flows and the Ina mounds (a lack of lunar inflation cracks and lava-rise pits) provide constraints to an inflation model. The age of Ina is not well constrained, but is an important aspect of its geologic history that needs to be addressed in future studies since it could influence models of formation. If the upper and lower units are similar in age, that would suggest contemporaneous emplacement, but if the ages are drastically different, then a multiphase eruption process will need to be considered.

[34] Acknowledgments. Lunar research was supported by the NASA Lunar Reconnaissance Orbiter Participating Scientist Program grants NNX11AG90G (PI: Garry), NNX08AM77G (PI: Hawke), and LROC Science Operations (PI: Robinson). Field work in Hawai'i, Idaho, and New Mexico was supported by the following grants: NASA Moon and Mars Analog Mission Activities (MMAMA) NNX08AR76G and NNX09AW15G (PI: Garry), 08-MMAMA08-016 (PI: Bleacher), NASA Planetary Geology and Geophysics (PGG) NNX09AD88G (PI: Zimbelman), Smithsonian Scholarly Studies Program FY11 (PI: Zimbelman). The authors would like to thank the Lunar Reconnaissance Orbiter Project Office at NASA Goddard Space Flight Center, the LROC Science Operations Center at Arizona State University, El Malpais National Monument in New Mexico, Craters of the Moon National Monument in Idaho, plus William J. Clancey and Maarten Sierhuis for their assistance with field work in Idaho and New Mexico. Thank you to Lazlo Keszthelyi, Peter H. Schultz, and an anonymous reviewer for their time and thorough reviews of the manuscript.

\section{References}

Anderson, S. W., E. R. Stofan, S. E. Smrekar, J. E. Guest, and B. Wood (1999), Pulsed inflation of pāhoehoe lava flows: Implications for flood basalt emplacement, Earth Planet. Sci. Lett., 168, 7-18, doi:10.1016/ S0012-821X(99)00044-8

Bleacher, J. E., W. B. Garry, J. R. Zimbelman, and L. S. Crumpler (2007), Insight into lava sheet inflation and deflation events from the McCartys flow, New Mexico, and implications for planetary lava flow emplacement, Eos Trans. AGU, 88(52), Fall Meet. Suppl., Abstract P34A-05.

Bleacher, J. E., W. B. Garry, and J. R. Zimbelman (2008), Observations of surface textures that are indicative of lava sheet inflation in monogenetic flow fields: Insights from the McCartys and Carrizozo flow fields, NM, Geol. Soc. Am. Abstr. Programs, 40(6), 114, Abstract 133-6.

Bray, V. J., et al. (2010), New insight into lunar impact melt mobility from the LRO camera, Geophys. Res. Lett., 37, L21202, doi:10.1029/ 2010GL044666.

Campbell, B. A., B. R. Hawke, L. M. Carter, R. R. Ghent, and D. B. Campbell (2009), Rugged lava flows on the Moon revealed by Earth-based radar, Geophys. Res. Lett., 36, L22201, doi:10.1029/2009GL041087.

Cashman, K. V., and J. P. Kauahikaua (1997), Reevaluation of vesicle distributions in basaltic lava flows, Geology, 25, 419-422, doi:10.1130/ 0091-7613(1997)025<0419:ROVDIB >2.3.CO;2. 
Cotton, C. A. (1952), Voclanoes as Landscape Forms, 416 pp., Hafner Publ., New York.

Daly, R. S. (1914), Igneous Rocks and Their Origin, 563 pp., McGraw Hill, New York.

El-Baz, F. (1973), D-caldera: New photographs of a unique feature, Apollo 17 Preliminary Sci. Rep., NASA SP 330, 30-13-30-17.

Evans, R. E., and F. El-Baz (1973), Geological observations from lunar orbit, Apollo 17 Preliminary Sci. Rep., NASA SP 330, 28-1-28-32.

Garry, W. B., J. R. Zimbelman, and J. E. Bleacher (2008), Morphology and emplacement processes at the distal end of the Carrizozo lava flow, New Mexico: Implications for Martian sheet flows, Lunar Planet. Sci., XXXIX Abstract 1734

Garry, W. B., J. R. Zimbelman, J. E. Bleacher, and L. S. Crumpler (2009), Topography and inflation features of the 1859 Mauna Loa lava flow, Hawai'i: Applications to inflated flows on Mars, Lunar Planet. Sci., $X X X X$, Abstract 1200

Giacomini, L., M. Massironi, E. Martellato, G. Pakquarè, A. Frigeri, and G. Cremonese (2009), Inflated flows on Daedalia Planum (Mars)? Clues from a comparative analysis with the Payen volcanic complex (Argentina), Planet. Space Sci., 57, 556-570.

Giguere, T. A., G. J. Taylor, B. R. Hawke, and P. G. Lucey (2000), The titanium contents of lunar mare basalts, Meteorit. Planet. Sci., 35, 193-200, doi:10.1111/j.1945-5100.2000.tb01985.x.

Greeley, R., and P. H. Schultz (1977), Possible planetary analogs to Snake River Plain basalt features, in Volcanism of the Eastern Snake River Plain, Idaho: A Comparative Planetary Geology Guidebook, edited by R. Greeley and J. S. King, pp. 233-251, Natl. Aeronaut. and Space Admin., Washington, D. C

Gregg, T. K. P., and J. H. Fink (1996), Quantification of extraterrestrial lava flow effusion rates through laboratory simulations, J. Geophys. Res., 101(E7), 16,891-16,900, doi:10.1029/96JE01254.

Gregg, T. K. P., and L. P. Keszthelyi (2004), The emplacement of pahoehoe toes: Field observations and comparisons to laboratory simulations, Bull. Volcanol., 66, 381-391, doi:10.1007/s00445-003-0319-5.

Hackman, R. J. (1966), Geologic map of the Montes Apenninus region of the Moon, U. S. Geol. Surv. Misc. Geol. Invest. Map, I-463, scale $1: 1,000,000$

Hawke, B. R., and C. R. Coombs (1987), Remote sensing studies of the Rima Hyginus region on the Moon, Lunar Planet. Sci., XVIII, 407-408.

Head, J. W., and A. Gifford (1980), Lunar mare domes: Classification and modes of origin, Earth Moon Planets, 22, 235-258, doi:10.1007/ BF00898434.

Head, J. W., D. B. Campbell, C. Elachi, J. E. Guest, D. P. McKenzie, R. S. Saunders, G. G. Schaber, and G. Schubert (1991), Venus volcanism: Initial analysis from Magellan data, Science, 252, 276-288, doi:10.1126/ science. 252.5003 .276

Hon, K., J. Kauahikaua, R. Denlinger, and K. Mackay (1994), Emplacement and inflation of pahoehoe sheet flows: Observations and measurements of active lava flows on Kilauea Volcano, Hawaii, Geol. Soc. Am. Bull., 106(3), 351-370, doi:10.1130/0016-7606(1994)106<0351: EAIOPS $>2.3 . \mathrm{CO} ; 2$

Hörz, F. (1977), Impact cratering and regolith dynamics, Phys. Chem Earth, 10, 3-15, doi:10.1016/0079-1946(77)90003-9.

Hulme, G. (1973), The interpretation of lava flow morphology, Geophys. J. R. Astron. Soc., 39, 361-383.

Hulme, G. (1982), A review of lava flow processes related to the formation of lunar sinuous rilles, Surv. Geophys., 5, 245-279, doi:10.1007/ BF01454018.

Kattenhorn, S. A., and C. J. Schaefer (2008), Thermal-mechanical modeling of cooling history and fracture development in inflationary basalt lava flows, J. Volcanol. Geotherm. Res., 170, 181-197, doi:10.1016/ j.jvolgeores.2007.10.002.

Keszthelyi, L. (2008), Inflated pahoehoe at Rima Hadley, Lunar Planet. Sci., XXXIX, Abstract 2339.

Keszthelyi, L., and R. Denlinger (1996), The initial cooling of pahoehoe flow lobes, Bull. Volcanol., 58, 5-18.

Keszthelyi, L., and A. McEwen (1997), Thermal models for basaltic volcanism on Io, Geophys. Res. Lett., 24, 2463-2466, doi:10.1029/ 97GL01368.

Keszthelyi, L. P., and D. C. Pieri (1993), Emplacement of the 75-km-long Carrizozo lava flow field, south-central New Mexico, J. Volcanol. Geotherm. Res., 59, 59-75, doi:10.1016/0377-0273(93)90078-6.

Keszthelyi, L., and S. Self (1998), Some physical requirements for the emplacement of long basaltic lava flows, J. Geophys. Res., 103(B11), 27,447-27,464, doi:10.1029/98JB00606.

Keszthelyi, L., A. S. McEwen, and T. Thordarson (2000), Terrestria analogs and thermal models for Martian flood lavas, J. Geophys. Res., 105(E6), 15,027-15,049, doi:10.1029/1999JE001191.
Keszthelyi, L., et al. (2001), Imaging of volcanic activity on Jupiter's moon Io by Galileo during the Galileo Europa Mission and the Galileo Millennium Mission, J. Geophys. Res., 106(E12), 33,025-33,052, doi:10.1029/ 2000JE001383.

Keszthelyi, L., T. Thordarson, A. McEwen, H. Haack, M. Guilbaud, S. Self, and M. Rossi (2004), Icelandic analogs to Martian flood lavas, Geochem. Geophys. Geosyst., 5, Q11014, doi:10.1029/2004GC000758.

Keszthelyi, L., W. Jaeger, A. McEwen, L. Tornabene, R. A. Beyer, C. Dundas, and M. Milazzo (2008), High Resolution Imaging Science Experiment (HiRISE) images of volcanic terrains from the first 6 months of the Mars Reconnaissance Orbiter Primary Science Phase, J. Geophys. Res., 113, E04005, doi:10.1029/2007JE002968.

Kuntz, M. A., E. C. Spiker, M. Rubin, D. E. Champion, and R. H. Lefebvre (1986), Radiocarbon studies of the latest Pleistocene and Holocene lava flows of the Snake River Plain, Idaho: Data, lessons, interpretations, Quat. Res., 25, 163-176, doi:10.1016/0033-5894(86)90054-2.

Kuntz, M. A., B. Skipp, D. E. Champion, P. B. Gans, D. Paco Van Sistine, and S. R. Snyders (2007), Geologic Map of the Craters of the Moon 30' $\times$ 60 ' Quadrangle, Idaho, U. S. Geol. Surv. Sci. Invest. Map, 2969, scale $1: 100,000$.

Lawson, S. L., W. C. Feldman, D. J. Lawrence, K. R. Moore, R. C. Elphic, R. D. Belian, and S. Maurice (2005), Recent outgassing from the lunar surface: The Lunar Prospector Alpha Particle Spectrometer, J. Geophys. Res., 110, E09009, doi:10.1029/2005JE002433.

Lucey, P. G., D. T. Blewett, and B. L. Jolliff (2000), Lunar iron and titanium abundance algorithms based on final processing of Clementine ultraviolet-visible images, J. Geophys. Res., 105(E8), 20,297-20,305, doi:10.1029/1999JE001117

Mattox, T. N., C. Heliker, J. Kauahikaua, and K. Hon (1993), Development of the 1990 Kalapana Flow Field, Kilauea Volcano, Hawaii, Bull. Volcanol., 55, 407-413, doi:10.1007/BF00302000

McKay, D. S., G. Heiken, A. Basu, G. Glanford, S. Simon, R. Reedy, B. M. French, and J. Papike (1991), The lunar regolith, in Lunar Sourcebook: A User's Guide to the Moon, edited by G. H. Heiken, D. T. Vaniman, and H. H. Schmitt, chap. 7, pp. 285-356, Cambridge Univ. Press, Cambridge, U. K.

Nichols, R. L. (1939), Surficial banding and shark's-tooth projections in the cracks of basaltic lava, Am. J. Sci., 237, 188-194, doi:10.2475/ ajs.237.3.188

Nichols, R. L. (1946), McCartys basalt flow, Valencia County, New Mexico, Geol. Soc. Am. Bull., 57, 1049-1086, doi:10.1130/0016-7606 (1946)57[1049:MBFVCN]2.0.CO;2.

Pavri, B., J. W. Head, K. B. Klose, and L. Wilson (1992), Steep-sided domes on Venus: Characteristics, geologic setting, and eruption conditions from Magellan data, J. Geophys. Res., 97(E8), 13,445-13,478, doi:10.1029/92JE01162.

Pike, R. J. (1978), Volcanoes on the inner planets: Some preliminary comparisons of gross topography, Proc. Lunar Planet. Sci. Conf., 9th 3239-3273.

Robinson, M. S., et al. (2010a), Lunar Reconnaissance Orbiter Camera (LROC) instrument overview, Space Sci. Rev., 150, 81-124, doi:10.1007/ s11214-010-9634-2.

Robinson, M. S., P. C. Thomas, S. E. Braden, S. J. Lawrence, and W. B. Garry, and the LROC Team (2010b), High resolution imaging of Ina: Morphology, relative ages, formation, Lunar Planet. Sci., XLI, Abstract 2592

Rowland, S. K., and G. P. L. Walker (1990), Pahoehoe and aa in Hawaii: Volumetric flow rate controls the lava structure, Bull. Volcanol., 52, 615-628, doi:10.1007/BF00301212.

Schaber, G. G. (1973), Lava flows in Mare Imbrium: Geologic evaluation from Apollo orbital photography, Proc. Lunar Sci. Conf., 4th, 73-92.

Schaefer, C. J., and S. A. Kattenhorn (2004), Characterization and evolution of fractures in low-volume pahoehoe lava flows, eastern Snake River Plain, Idaho, Geol. Soc. Am. Bull., 116, 322-336, doi:10.1130/B25335.1.

Scholten, F., J. Oberst, K. D. Matz, T. Roatsch, M. Wählisch, and M. S Robinson (2011), GLD100 - The global lunar 100 meter raster DTM from LROC WAC stereo models, Lunar Planet. Sci., XXXXII, Abstract 2046. Schultz, P. H. (1976), Moon Morphology, 626 pp., Univ. of Texas Press, Austin, Texas.

Schultz, P. H., R. Greeley, and D. E. Gault (1976), Degradation of small mare surface features, Proc. Lunar Sci. Conf., 7th, 985-1003.

Schultz, P. H., M. I. Staid, and C. M. Pieters (2000), Recent lunar activity: Evidence and implications, Lunar Planet. Sci., XXXI, Abstract 1919.

Schultz, P. H., M. I. Staid, and C. M. Pieters (2006), Lunar activity from recent gas release, Nature, 444, 184-186, doi:10.1038/nature05303.

Self, S., T. Thordarson, L. Keszthelyi, G. P. L. Walker, K. Hon, M. T. Murphy, P. Long, and S. Finnemore (1996), A new model for the emplacement of Columbia River basalts as large, inflated pāhoehoe 
lava flow fields, Geophys. Res. Lett., 23, 2689-2692, doi:10.1029/ 96GL02450.

Self, S., T. Thordarson, and L. Keszthelyi (1997), Emplacement of continental flood basalt lava flows, in Large Igneous Provinces: Continental, Oceanic, and Planetary Flood Volcanism, edited by J. J. Mahoney and M. F. Coffin, pp. 381-410, AGU, Washington, D. C., doi:10.1029/ GM100p0381.

Self, S., L. Keszthelyi, and T. Thordarson (1998), The importance of Pahoehoe, Annu. Rev. Earth Planet. Sci., 26, 81-110, doi:10.1146/annurev. earth.26.1.81.

Smith, D. E., et al. (2010), The Lunar Orbiter Laser Altimeter investigation on the Lunar Reconnaissance Orbiter Mission, Space Sci. Rev., 150, 209-241, doi:10.1007/s11214-009-9512-y.

Staid, M., P. Isaacson, N. Petro, J. Boardman, C. M. Pieters, J. W. Head, J. Sunshine, K. Donaldson Hanna, L. A. Taylor, and the $\mathrm{M}^{3}$ Team (2011), The spectral properties of Ina: New observations from the Moon Mineralogy Mapper, Lunar Planet. Sci., XLII, Abstract 2499

Stofan, E. R., S. W. Anderson, D. A. Crown, and J. J. Plaut (2000), Emplacement and composition of steep-sided domes on Venus, J. Geophys. Res., 105(E11), 26,757-26,771, doi:10.1029/1999JE001206.

Stooke, P. J. (2012), Lunar meniscus hollows, Lunar Planet. Sci., XLIII, Abstract 1011 .

Strain, P. L., and F. El-Baz (1980), The geology and morphology of Ina, Proc. Lunar Planet. Sci. Conf., 11th, 2437-2446.

Thordarson, T., and S. Self (1998), The Roza Member, Columbia River Basalt Group: A gigantic pahoehoe lava flow field formed by endogenous processes?, J. Geophys. Res., 103(B11), 27,411-27,445, doi:10.1029/ 98JB01355.

Tran, T., et al. (2010), Generating digital terrain models from LROC stereo images with SOCET set, Lunar Planet. Sci., XLI, Abstract 2515.

Tran, T., M. S. Robinson, S. J. Lawrence, S. E. Braden, J. Plescia, B. R. Hawke, B. L. Jolliff, and J. D. Stopar, and the LROC Team (2011) Morphometry of lunar volcanic domes from LROC, Lunar Planet. Sci., XLII, Abstract 2228
Walker, G. P. L. (1991), Structure, and origin by injection of lava under surface crust, of tumuli, "lava rises", "lava-rise pits", and "lava-inflation clefts" in Hawaii, Bull. Volcanol., 53(7), 546-558, doi:10.1007/ BF00298155.

Walker, G. P. L. (2009), The endogenous growth of pahoehoe lava lobes and morphology of lava-rise edges, in Studies in Volcanology: The Legacy of George Walker, edited by T. Thordarson et al., pp. 17-32, Geol. Soc., Bath, U. K.

Wentworth, C. K., and G. A. Macdonald (1953), Structures and forms of basaltic rocks in Hawaii, U. S. Geol. Surv. Bull., 994, 98 pp.

Whitaker, E. A. (1972), An unusual mare feature, NASA Spec. Publ., 289, $25-84-25-85$

Whitford-Stark, J. L., and J. W. Head (1977), The Procellarum volcanic complexes: Contrasting styles of volcanism, Proc. Lunar Sci. Conf., 8th, 2705-2724.

Wilcox, B. B., M. S. Robinson, P. C. Thomas, and B. R. Hawke (2005), Constraints on the depth and variability of the lunar regolith, Meteorit Planet. Sci., 40, 695-710, doi:10.1111/j.1945-5100.2005.tb00974.x.

Wilhelms, D. E., and J. F. McCauley (1971) Geologic map of the near side of the Moon, U. S. Geol. Surv. Misc. Geol. Invest. Map, I-703.

Wilson, L., and J. W. Head (2008), Eruption rates of mare lava flows on the Moon and implications for mantle melt volumes and dike geometries, Lunar Planet. Sci., XXXIX, Abstract 1104.

Zimbelman, J. R., and A. K. Johnston (2001), Improved topography of the Carrizozo lava flow: Implications for emplacement conditions, in Volcanology in New Mexico, N. M. Museum Nat. Hist. Sci. Bull., 18, 131-136.

Zimbelman, J. R., W. B. Garry, J. E. Bleacher, and L. S. Crumpler (2009), Identifying inflation characteristics of lava flows on Earth and Mars, Geol. Soc. Am. Abstr. Programs, 41(7), 259, Abstract 95-4.

Zimbelman, J. R., W. B. Garry, L. S. Crumpler, and J. E. Bleacher (2010), Field investigations of inflated pahoehoe basalt lava flows, with application to lava flows on other planets, Lunar Planet. Sci., XLI, Abstract 1826. 